\title{
Signal and noise levels in numerical scattering chamber snapshots
}

S. A. Swift, W.S. Little, and R.A. Stephen

Department of Geology and Geophysics

Woods Hole Oceanographic Institution

Woods Hole, MA 02543

May 1995

Technical Memorandum

This work was carried out under ONR Grant \#N00014-90-J-1493
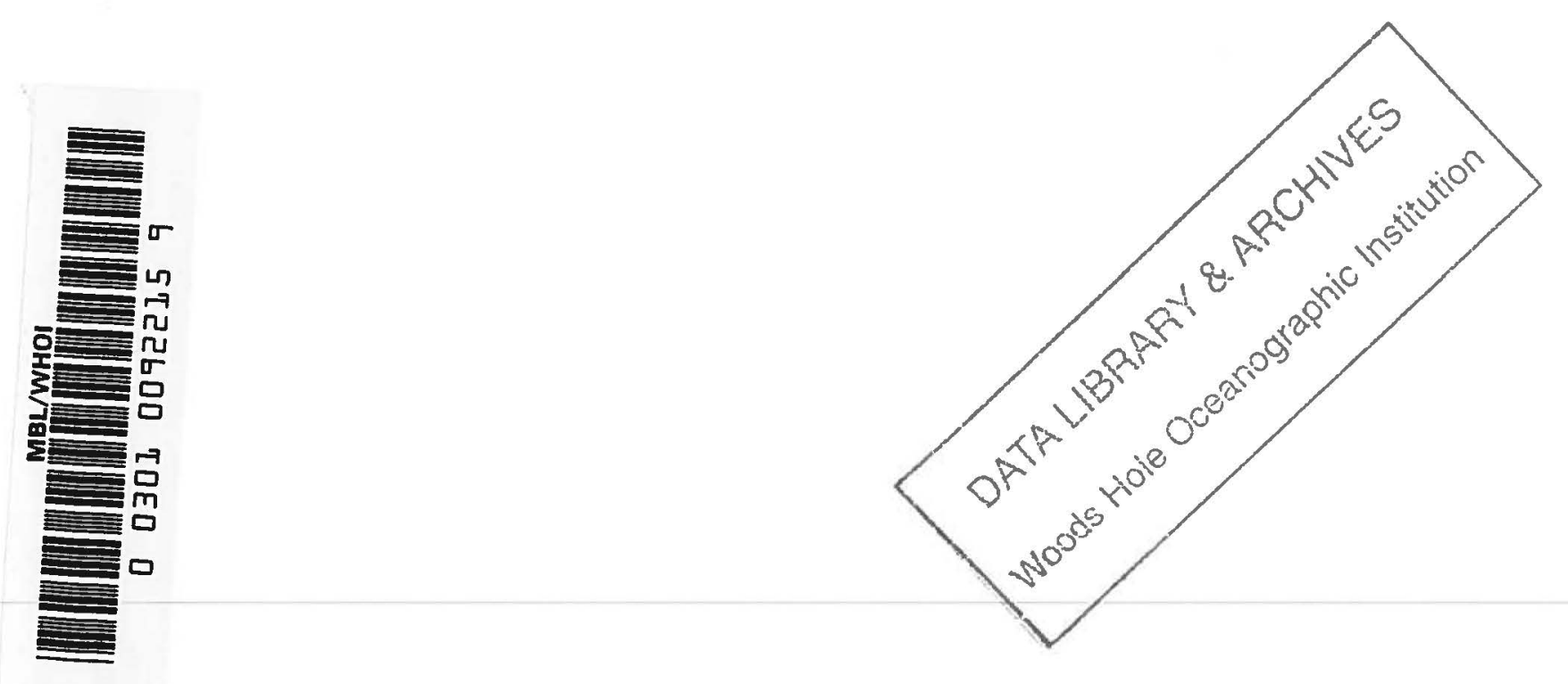


\section{INDEX}

Index

page number

2

Figure and Table Summary

3

Abstract

4

Introduction

4

Models Used in Study

5

Methods

6

Results

7

Conclusions

10

References

Figures

Tables

31

Appendix I: Parameter files for models 


\section{FIGURE AND TABLE SUMMARY}

Figure 1. Numerical Schlieren diagrams

page number

Figure 1a. fig920500b and fif 890500 hgdg2

Figure 1b. fig920650b and fif 890650 hgdg2

Figure 1c. fifb60500 and fif 890500 teg3

Figure 1d. fifb60650 and fif890650teg3

Figure 1e. fig $150500 \mathrm{~b}$ and fif 890500 teg3

Figure 1f. fig150650b and fif890650teg3

$\begin{array}{lll}\text { Figure 2. } & \text { Plots of compressional energy amplitude }\end{array}$

Figure 2a. Fig920500B. No heterogeneities. Higdon boundaries. 19

Figure 2b. Fig920650B. No heterogeneities. Higdon boundaries. 20

Figure 2c. Fif890500hgd. $k a=1$. Higdon boundaries. 21

Figure 2d. Fif890650hgd. $k a=1$. Higdon boundaries. 22

Figure 2e. Fifb60500. No heterogeneities. Telegraph Eqn. Convex. 23

Figure 2f. Fifb60650. No heterogeneities. Telegraph Eqn. Convex. 24

Figure 2g. Fig150500. No heterogeneities. Telegraph Eqn. Gannet. 25

Figure 2h. Fig150650. No heterogeneities. Telegraph Eqn. Gannet 26

Figure 2i. Fif890500te. $k a=1$. Telegraph Eqn boundaries. 27

Figure 2j. Fif890650te. $k a=1$. Telegraph Eqn boundaries. 28

$\begin{array}{ll}\text { Figure 3: } & \text { Representative snapshots }\end{array}$

Figure 4: Data traces along the grid row at the top of basement 30

Table 1: $\quad$ Summary of models used in amplitude study 31

Table 2: $\quad$ Amplitude data for snapshots $\quad 32$ 


\begin{abstract}
A study was carried out to quantify the level of numerical noise in numerical scattering chamber (NSC) calculations and to compare these noise levels with signal levels of body waves, interface waves and ambient noise. The amplitudes of signal and noise in snapshots from the numerical scattering chamber were quantified at 50 and 65 periods for a few reference models. Models with homogeneous subseafloor structure were studied to determine the level of numerical noise; models with a wavenumber-correlation length product of one were examined to determine signal levels. Models were run with both Higdon and telegraph equation absorbing boundaries since the numerical noise within the grid depends on the boundary formulation. Amplitudes were measured along data traces obtained at a grid depth of $3.33 \lambda_{\mathrm{W}}$ and at the seafloor. Forward traveling head waves had typical amplitudes of \pm 125 but may reached \pm 250 near the direct wave. Diffraction amplitudes were observed up to \pm 300 . Stoneley wave amplitudes ranged from \pm 800 up to $\pm 20,000$. Numerical noise levels were less than \pm 25 in most areas of the water and less than \pm 350 along most of the seafloor. Regardless of the absorbing boundary type, however, there was a region of noise extending up to $15 \lambda_{\mathrm{W}}$ behind the first seafloor reflection at $3.33 \lambda_{\mathrm{W}}$ in which noise levels range from \pm 100 up to \pm 600 . In this region it is difficult to resolve signal from systematic numerical noise.
\end{abstract}

\title{
INTRODUCTION
}

This report documents the relative amplitudes of signal and noise in output from finite difference computations done in the Numerical Scattering Chamber (Stephen and Swift, 1994). This information is of use in discriminating and evaluating signal in results from the NSC, in determining gray scales with which to display snapshots, and in quality control. This study was undertaken for the purpose of identifying effects from absorbingboundary conditions used in the finite difference computations and features of the 
water/seafloor models which contribute excessive amounts of noise. Once the conditions leading to excessive noise can be identified, the noisy models can be either modified or avoided. In models in which the amplitudes of noise and the principle signal features do not overlap, gray scales for graphic display can be designed to suppress noise while preserving the character of the signal.

\section{MODELS USED IN STUDY}

Table 1 lists the five different models included in this compilation. The velocity/density characteristics below the seafloor were chosen to simulate the top of ocean basement. In all models the seafloor was a flat surface located at row 93 in the boundary grid file. All models were run at 15 points per wavelength. Models with homogeneous basement were used to evaluate the magnitude of numerical noise and models with heterogeneous basement were used to estimate the amplitude of scattered phases. The heterogeneities in these latter models were determined by creating a grid of random velocities with a Gaussian distribution in velocity. The grid was then filtered with a twodimensional Gaussian spatial filter. The resulting velocity anomalies had characteristic length scales such that $k a=1$ (where $k=2 \pi / \lambda$ is the wave number, $a$ is the length scale of the heterogeneity, and $\lambda$ is the wavelength in water at the peak frequency in pressure of the source). There were no vertical gradients in either the mean velocity or in the amplitude of the velocity variations.

This study includes two models which are described in Swift and Stephen (1994). FIG92 is a laterally homogeneous model and FIF89 is a laterally heterogeneous model with $\mathrm{ka}=1$. Snapshots were obtained by rerunning the models on the DEC Alpha 3000 (eg. Gannet; Table 1). These models are compared to movie snapshots from a laterally homogeneous model FIFB6 run on the Convex. The available parameter and log files are provided in the Appendix. FIG15 is a laterally homogeneous model which uses telegraph equation (t.e.) abosrbing boundaries. FIG92 uses Higdon boundaries (Higdon, 1986; 
Higdon, 1987; Higdon, 1990; Higdon, 1991). The heterogeneous model (FIF89) was run with both telegraph equation and Higdon boundaries.

The models were run with two types of absorbing boundaries to determine the relative efficiency of the boundary conditions. Initially, the absorbing boundaries in the NSC were based on the telegraph equation (Dougherty and Stephen, 1988; Levander, 1985). Later, narrower boundaries as described by Higdon (1991) were introduced to shorten computation time. One objective of this study was to determine if there was a cost in terms of increased noise for using the faster Higdon boundaries.

Note that the velocity and density of FIFB6 differ slightly from the rest. Model FIFB6 was run with VP2 $=3.0$, VS2 $=1.73$, and $\mathrm{RO} 2=1.7$. The other models were run such that the mean basement parameters were VP2 $=3.2$, VS2 $=1.8475$, and RO2 $=1.4642$. For all models, constraints were placed on the values of velocity and density to stabilize the finite difference computation. In all models other than FIFB6, the maximum compressional velocity in the uppermost row was fixed at $3.0 \mathrm{~km} / \mathrm{s}$. Maximum compressional velocities in the next two rows were constrained to $3.99 \mathrm{~km} / \mathrm{s}$. Throughout the basement layer in all models, the minimum compressional velocity was fixed at $2.0 \mathrm{~km} / \mathrm{s}$.

\section{METHODS}

To evaluate relative signal and noise, compressional energy snapshots from models with lateral heterogeneities were compared to homogeneous models. Snapshots were examined at time step $5000\left(50 \mathrm{P}_{\mathrm{W}}\right.$, where $\mathrm{P}_{\mathrm{W}}$ is the period of the peak frequency of the source in pressure) and at time step $6500\left(65 \mathrm{P}_{\mathrm{W}}\right)$ to determine how noise develops with time across the scattering chamber. Figure 1 shows frames in which a snapshot from a model with heterogeneities is compared to a snapshot from a homogeneous model. The seafloor appears at a depth of $6.20 \lambda_{\mathrm{w}}$. A continuous gray scale from $+10,000$ to $-10,000$ was used in all frames. As a reference level, the largest amplitude of the incident beam in 
all the traces recorded from the NSC was 64,372 . This value is the same for all models in this report.

To quantitatively compare the snapshots, the amplitudes at an arbitrarily determined depth in the water ( $\left.3.33 \lambda_{\mathrm{w}}\right)$ were extracted from the compressional snapshot data files and plotted at three amplitude scaling factors (Figure 2). This grid row crosses most of the noise and signal features. The approximate comparison depth is shown by a heavy horizontal line in the snapshots in Figure 1. The depth was chosen at grid row 50 in the Gannet snapshots. The Convex snapshots (FIFB6) were produced for use in a movie and as a result were somewhat smaller. For this model data from grid row 29 was extracted. The snapshots of the homogeneous models show energy trapped along the seafloor interface (Figure 1). The amplitude of this energy peaks at the seafloor (grid row 93, 6.20 $\left.\lambda_{\mathrm{w}}\right)$ and decays rapidly away from the interface. Both the amplitude and the apparent period decrease to the left in the opposite direction of the propagation of the source pulse. To compare this noise to Stoneley waves in the laterally heterogeneous model, data were also extracted at the seafloor $\left(6.20 \lambda_{w}\right)$ and plotted (Figure 4).

To aid in comparison, the amplitude range of several signal and noise features were picked from the plots at rows $3.33 \lambda_{\mathrm{W}}$ and $6.20 \lambda_{\mathrm{W}}$ (Figures 2 and 4). Table 2 summarizes these amplitudes for each model. The maximum and minimum amplitudes of individual peaks were picked when the feature consisted of a short wavelet. Approximate ranges were determined for features with greater spatial extent.

\section{RESULTS}

Interesting features in the snapshots are the head waves to the right of the direct wave and the diffracted energy in the water behind the direct wave and first seafloor reflection (Figure 4). Backward traveling head wave energy is included in the latter, but it can not be resolved in the snapshots or the line graphs. Stoneley waves along the seafloor 
interface are also of interest. Interface waves do not enter the backscatter calculation but they scatter energy upwards and, thus, are an important feature to image.

The numerical noise was estimated by measuring amplitudes in the homogeneous models. The velocity contrasts at the seafloor should produce total internal reflection. Since there are no velocity anomalies in the basement, there is no mechanism to scatter energy which leaks below the seafloor in the direct wave root (Swift and Stephen, 1994). Ahead of the direct wave, amplitude variations are less than \pm 5 (Figures $2 \mathrm{a}, 2 \mathrm{e}, 2 \mathrm{~g}$; Figure 3; Table 2). (Numerical values at grid points become non-zero at the rate of one grid-point per time step $(0.01 \mathrm{~km} / 0.001 \mathrm{~s}=10 \mathrm{~km} / \mathrm{sec})$ and move out across the grid isotropically regardless of the physical propagation of sound. These values ahead of the direct and head waves are one type of 'numerical noise'.) In comparison, forward propagating head waves in heterogeneous models have amplitudes ranging from about \pm 250 near the direct wave to \pm 90 farther away (Figures 2c, 2i; Table 2). These head waves are clearly resolvable above the local numerical noise. Behind the seafloor reflection and its multiples, numerical noise in the water for homogeneous models is less than \pm 25 at 50 periods and less than \pm 10 at 65 periods. Diffracted energy in heterogeneous models for this region ranges from \pm 75 to \pm 300 . Thus, the phases contributing to upwards scattering in heterogeneous models clearly exceed the local numerical noise levels.

Stoneley wave energy at the seafloor in the heterogeneous models ranges from \pm 800 to $\pm 20,000$ (Table 2). In homogeneous models, a peculiar oscillation occurs at the interface (Figure 4). An initial wavelet with amplitude $\pm 2,800$ occurs at the point where the direct wave reflects from the seafloor. Behind this spike an oscillation appears decreasing in amplitude but increasing in frequency with greater distance/time away from the direct wave. The maximum amplitude of the oscillation $( \pm 330)$ is a factor of two less than the smallest Stoneley waves observed. The form and amplitude of the Stoneley waves observed in heterogeneous models away from the first reflection point are relatively unaffected by numerical noise. This oscillation is related to the manner in which elastic 
parameters are defined at the seafloor and it is discussed further by Stephen and Swift (in prep)

The principal noise features are the water wave multiples caused by imperfect absorbing boundaries. Two multiples can often be resolved in snapshots from models run with Higdon boundaries (eg. model FIG92 in Figure 1). The amplitude of the first multiple clearly increases from 50 to 65 periods. This change is likely due to non-uniform energy distribution across the Gaussian pulse-beam used in the NSC as a source. In the homogeneous models, there is a region of noise that trails the positive spike of the first seafloor reflection (Figures 2a,b,e,f,g,h). Amplitudes decay to the left from about \pm 1000 immediately next to the first reflection to background noise levels of \pm 10 to \pm 25 over about $15 \lambda_{\mathrm{w}}$. The type of absorbing boundary used in the computation does not affect the amplitude of the noise in this region. The type of absorbing boundary only determines whether noise occurs in the laterally coherent form of a first multiple. Other causes of this noise are numerical dispersion from propagation in the homogeneous water coulmn or ringing behind the seafloor reflection caused by incorrect treatment at the seafloor. The arrival about $52 \lambda_{\mathrm{w}}$ in the $65 \mathrm{P}$ traces (Figure $2 \mathrm{~b}$ ) is caused by truncation of the source time series. This event has a maximum amplitude of +100 in this figure and is generally below the signal levels of interest. It is also discussed further in Stephen and Swift (Stephen and Swift, in prep).

The first multiple from the absorbing boundary can be confidently identified only in the 65 period snapshots and amplitude traces from Higdon boundary models, although there is some suggestion of the first multiple at $43 \lambda_{\mathrm{w}}$ in the FIG92 snapshot at 50 periods (Figures 1a and 2a). At a grid depth of $3.33 \lambda_{\mathrm{w}}$ (Figure 2), the general pattern in amplitude covers about 3-4 $\lambda_{\mathrm{W}}$ and has an amplitude of about +400 to -700 . From right to left the multiple begins with a negative spike at the leading edge of the down-going reflection off the lid of the model. This is followed by a broader positive pulse that is the sum of the trailing pulse in the lid reflection and the leading positive pulse in the second 
seafloor reflection. Last, is a positive spike that is the trailing pulse of the seafloor reflection couplet.

The second multiple is centered at about $38 \lambda_{\mathrm{w}}$ in the snapshot at 50 periods and at about $53 \lambda_{w}$ in the snapshot at 65 periods. The amplitude range is typically -40 to +120 . The second multiple can be easily identified in all models with homogeneous basement structure regardless of the type of absorbing boundary used. The second multiple probably also occurs in the $k a=1$ models but cannot be easily resolved because its amplitude is less than that of the diffracted energy. This event is a truncation effect which occurs when the source function is turned off (see above) and is not a proper 'multiple'.

\section{CONCLUSIONS}

Noise in the NSC finite difference computations is less than the signals of interest in most parts of the grid. Noise levels rarely rise above \pm 25 in the water and rarely exceed \pm 350 at the seafloor. Signal levels are generally above \pm 100 in the water and above \pm 800 at the seafloor. A gray scale that did not display amplitudes below 50-80 would effectively eliminate most of the noise in the water. At the seafloor the amplitude of the signal in heterogeneous models so far exceeds the noise that an adjustment in gray scale is not necessary to enhance the display. Trailing the first seafloor reflection by up to $15 \lambda_{\mathrm{w}}$ (at a grid depth of $3.33 \lambda_{\mathrm{W}}$ ), there is a region of noise with amplitudes reaching up to about \pm 1000 independent of the type of absorbing boundary. This energy can not be suppressed in the snapshots by an artful gray scale without suppressing signals and diffractions elsewhere in the grid. Using the telegraph equation absorbing boundary instead of Higdon removes features in this region that are false reflections from the abosrbing boundary. However three other features persist: the truncation of the source, the false treatment of the seafloor and numerical dispersion (see Figures $2 \mathrm{~b}, 2 \mathrm{~d}, 2 \mathrm{f}, 2 \mathrm{~h}$ ). 


\section{REFERENCES}

Dougherty, M.E., and Stephen, R.A. (1988). "Seismic energy partitioning and scattering in laterally heterogeneous ocean crust," Pure Appl. Geophys. 128, 195-229.

Higdon, R.L. (1986). "Absorbing boundary conditions for difference approximations to the multidimensional wave equation," Math. Comp. 47, 437-459.

Higdon, R.L. (1987). "Numerical absorbing boundary conditions for the wave equation," Math. Comp. 49, 65-90.

Higdon, R.L. (1990). "Radiation boundary conditions for elastic wave propagation," SIAM Journal of Numerical Analysis 27, 831-870.

Higdon, R.L. (1991). "Absorbing boundary conditions for elastic waves," Geophysics 56, 231241.

Levander, A.R. (1985). "Use of the telegraphy equation to improve absorbing boundary efficiency for fourth-order acoustic wave finite difference schemes," Bull. Seismol. Soc. Am. 75, 18471852.

Stephen, R.A., and Swift, S.A. (1994). "Modeling seafloor geoacoustic interaction with a numerical scattering chamber," J. Acoust. Soc. Am. 96, 973-990.

Stephen, R.A., and Swift, S.A., (in prep). Numerical noise and artifacts in the numerical scattering chamber. Woods Hole Oceanographic Institution.

Swift, S.A., and Stephen, R.A. (1994). "The scattering of a low-angle pulse beam by seafloor volume heterogeneities," J. Acoust. Soc. Am. 96, 991-1001. 


\section{Higdon Boundaries}

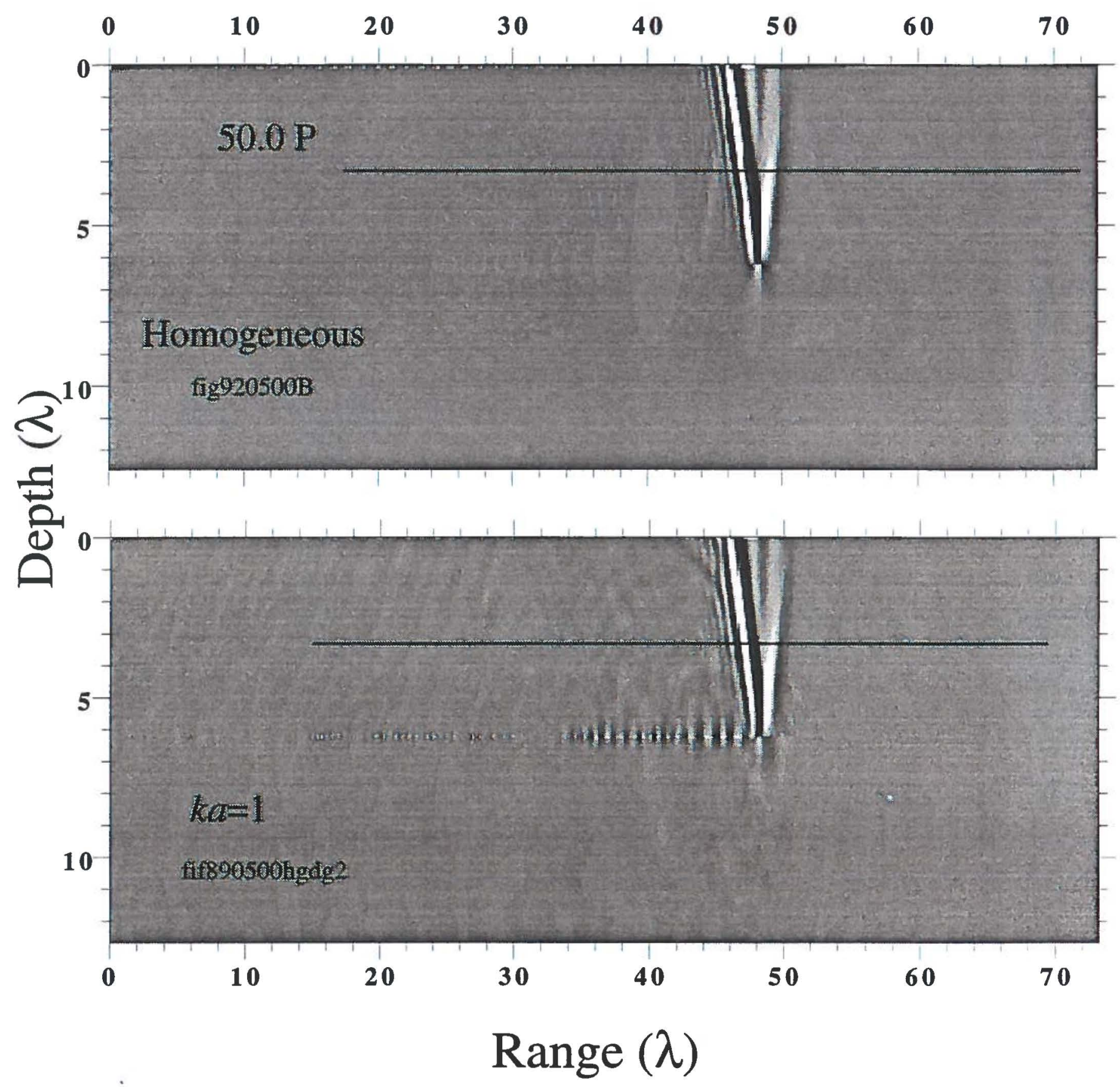

Figure 1. Numerical Schlieren diagrams (snapshot) showing compressional energy distribution at 50 periods $(\mathrm{P})$. The top frame shows a model with homogeneous structure below the seafloor. The bottom frame shows a model with velocity heterogeneities with length scales such that $k a=1$ (no vertical gradients). The solid black line approximately marks the depth at which the data for the amplitude plots (Figure 2) were plotted. See Figure 4 for locations of signal and noise features mentioned in the text. 
Figure 1b. fig920650b and fif890650hgdg2

Higdon Boundaries

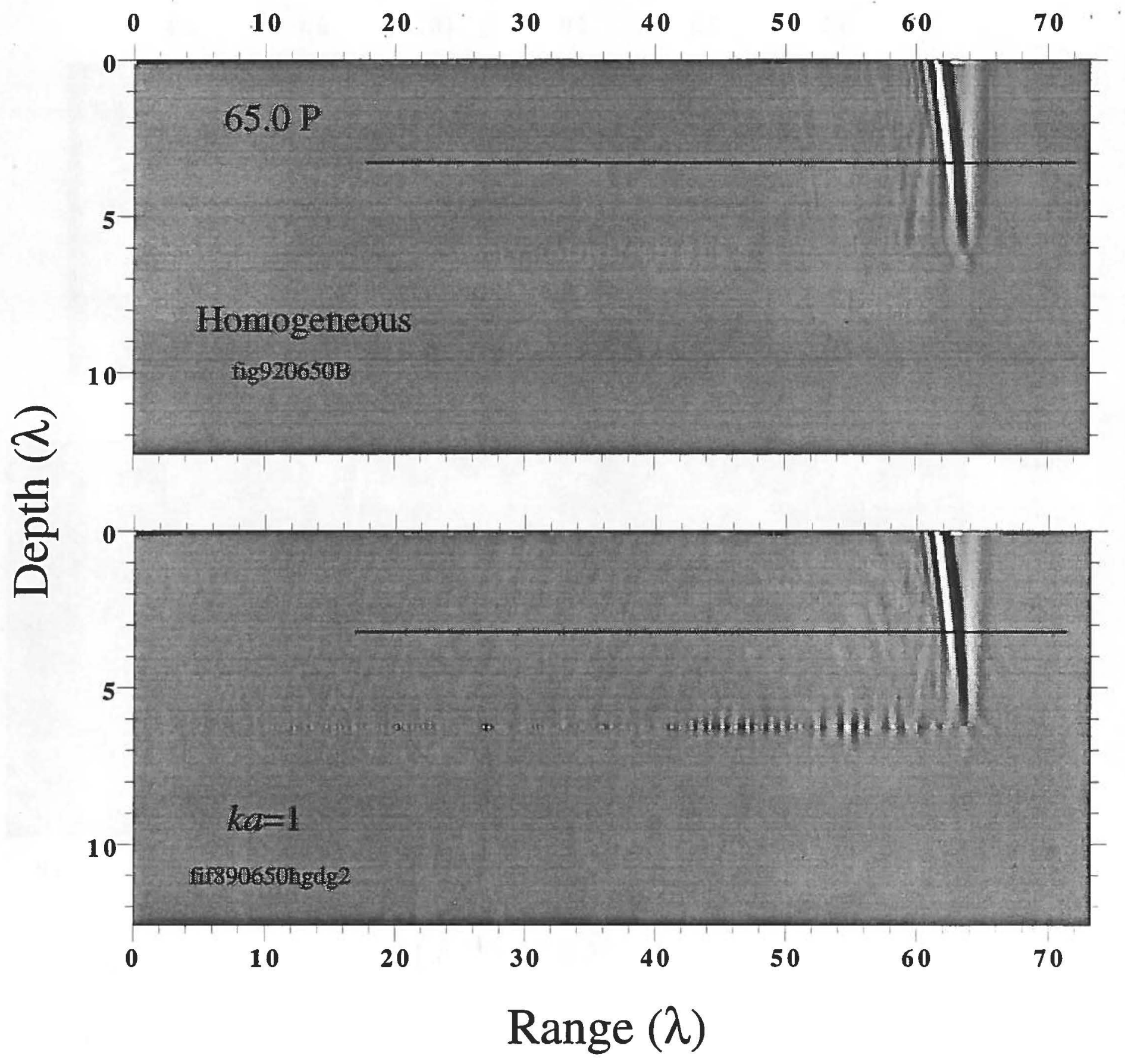


Figure 1c. fifb60500 and fif890500teg3

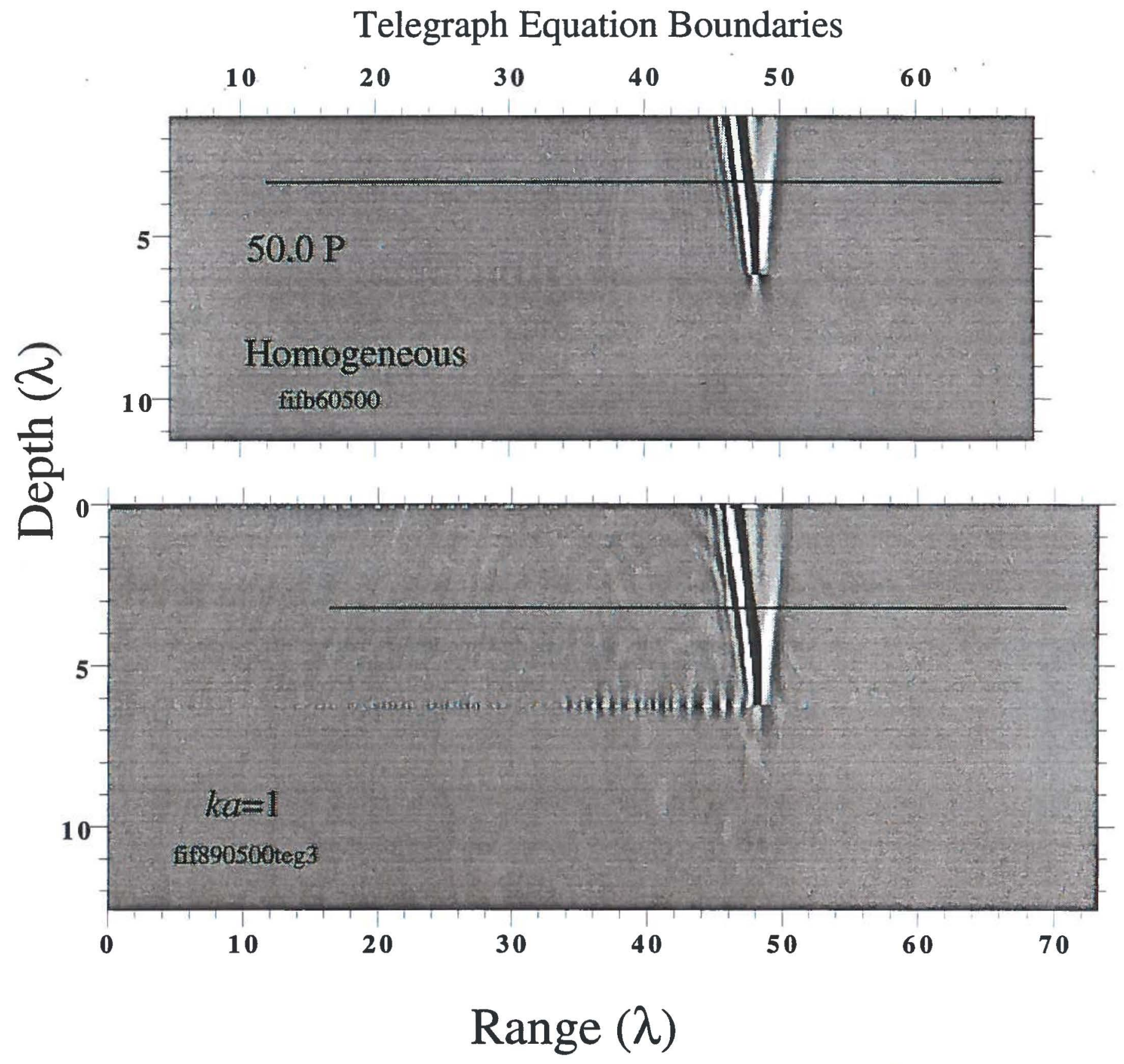


Figure 1d. fifb60650 and fif890650teg3

\section{Telegraph Equation Boundaries}

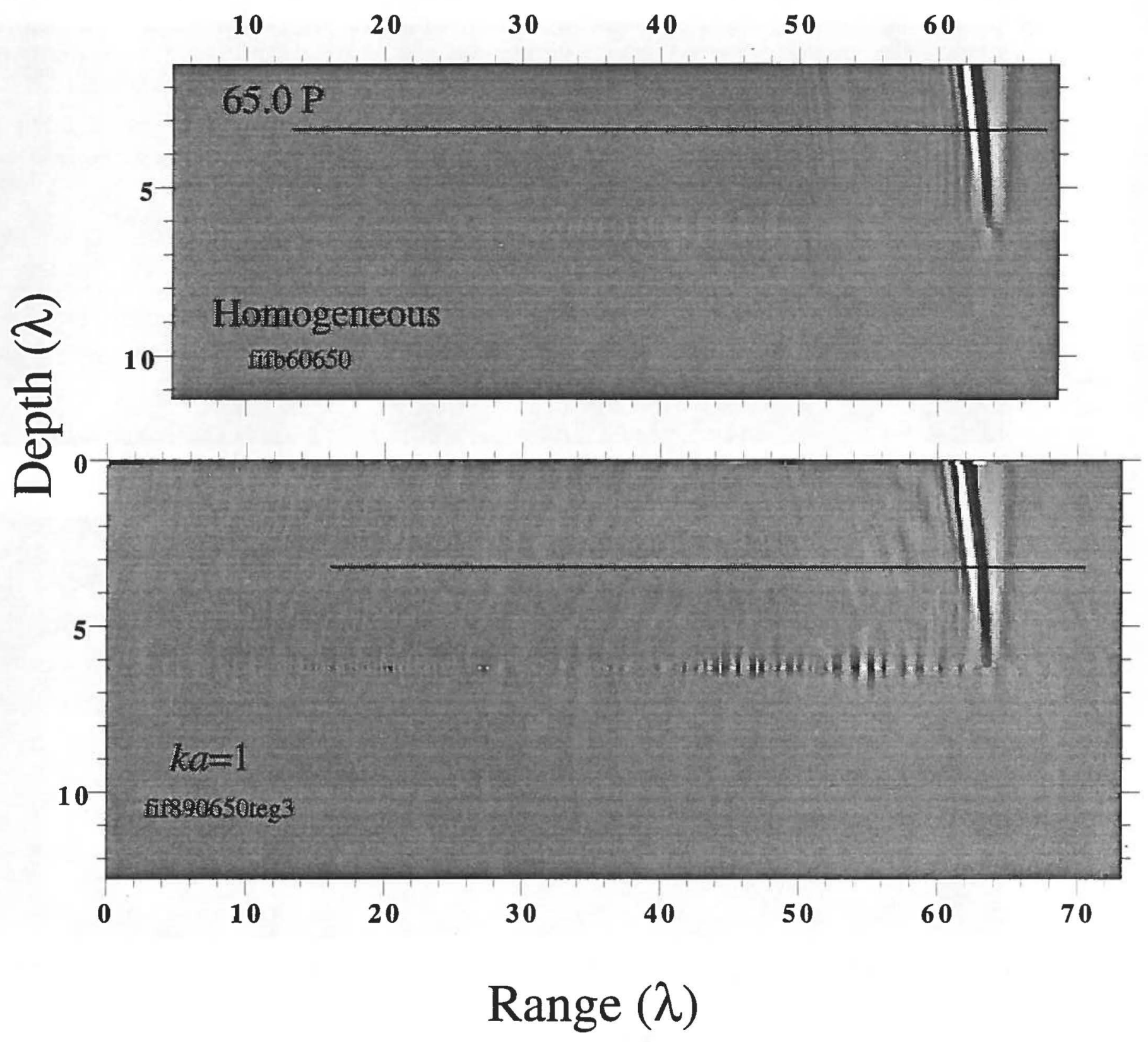


Figure le. fig $150500 \mathrm{~b}$ and fif890500teg3

Telegraph Equation Boundaries

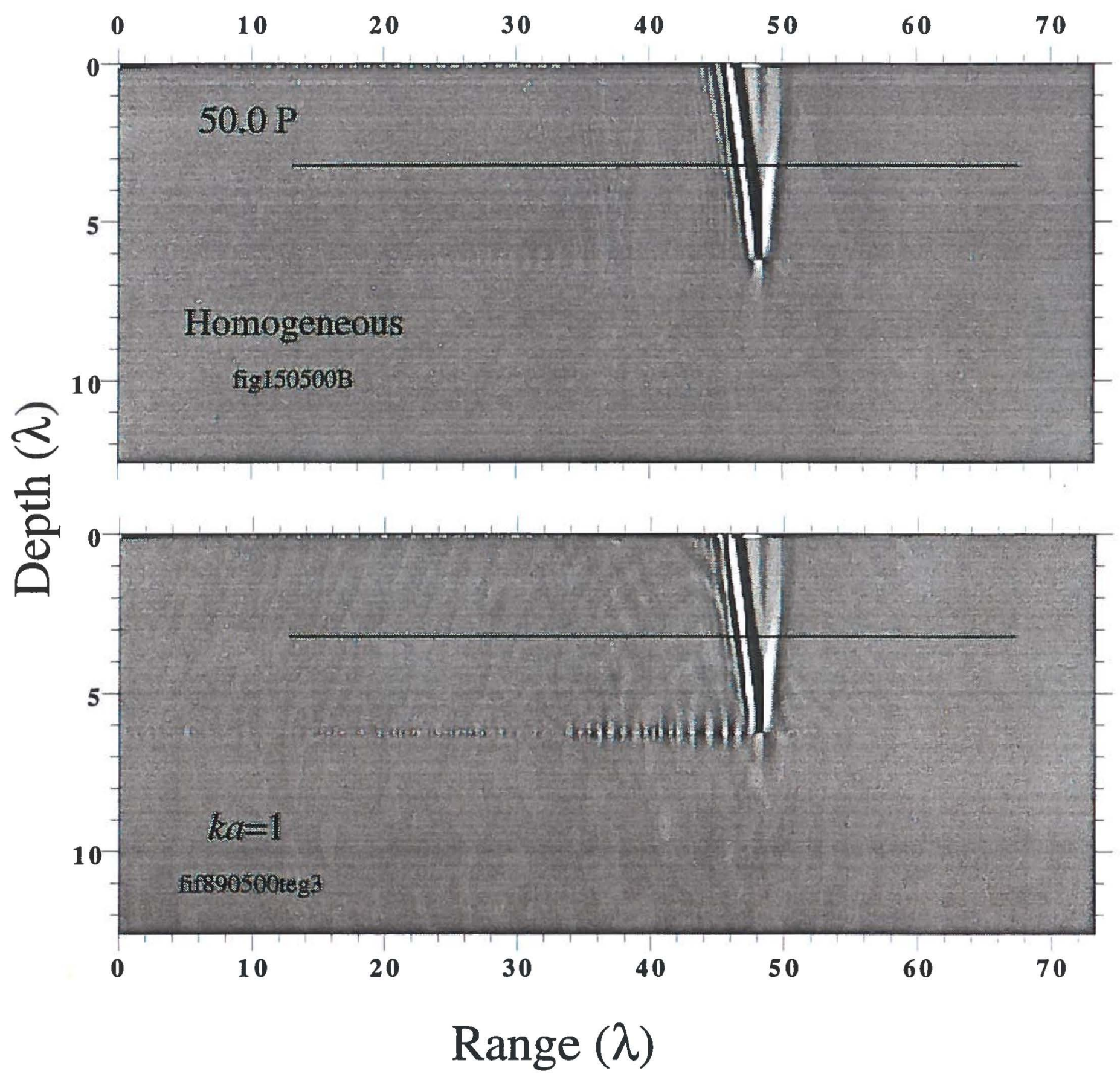


Figure 1f. fig $150650 \mathrm{~b}$ and fif890650teg3

Telegraph Equation Boundaries

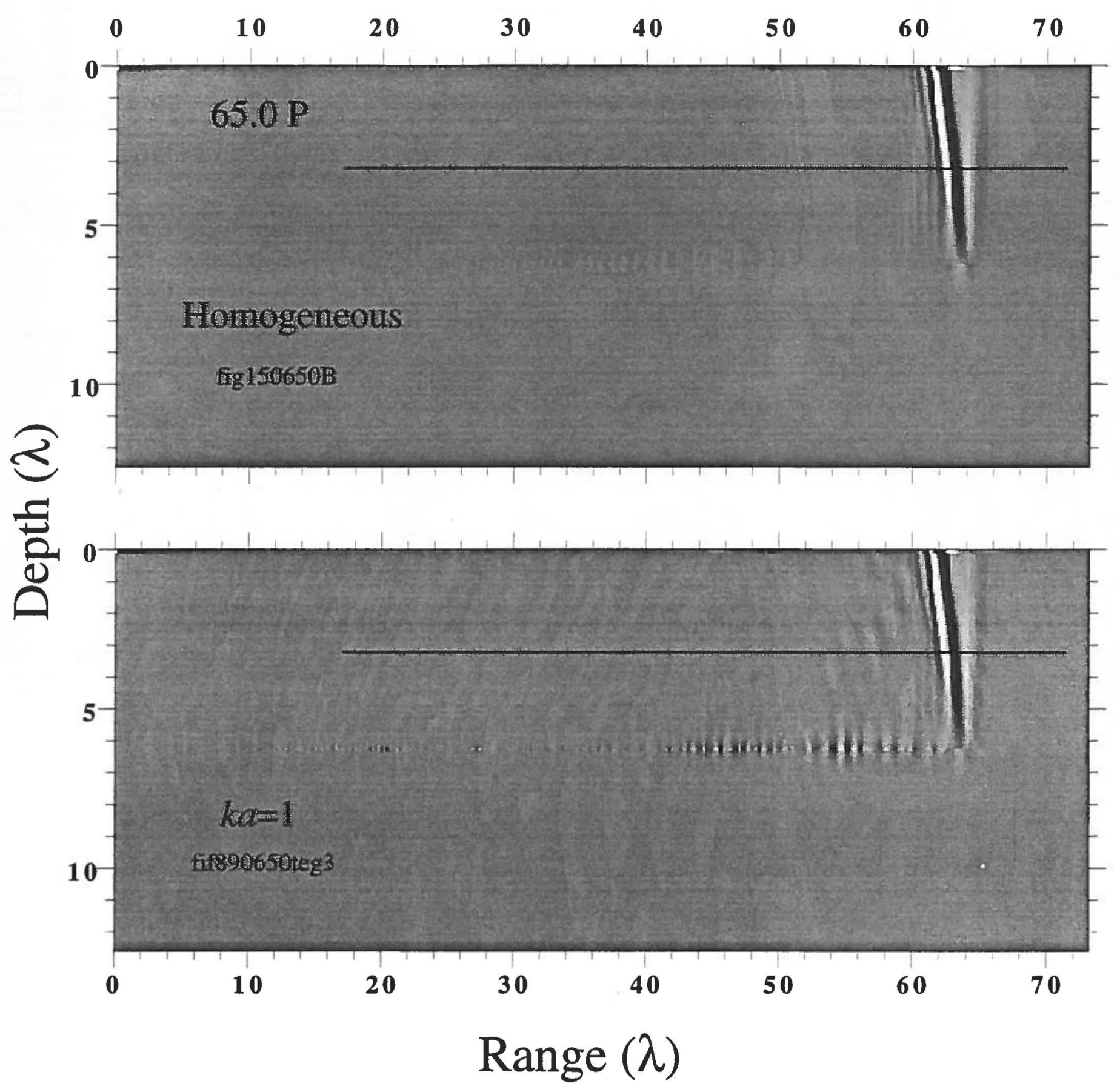


Figure 2. Plots of compressional energy amplitude along a horizontal trace at a grid depth of $3.33 \lambda_{\mathrm{W}}$ for each model studied. Each frame shows the same data plotted at a different amplitude scale. Particular noise features are indicated by letters: A - reflection from poor absorbing boundary; B - numerical dispersion; C - truncation of the source; D - incorrect treatment of flat seafloor. 
Figure 2b. Fig920650B. No heterogeneities. Higdon boundaries.
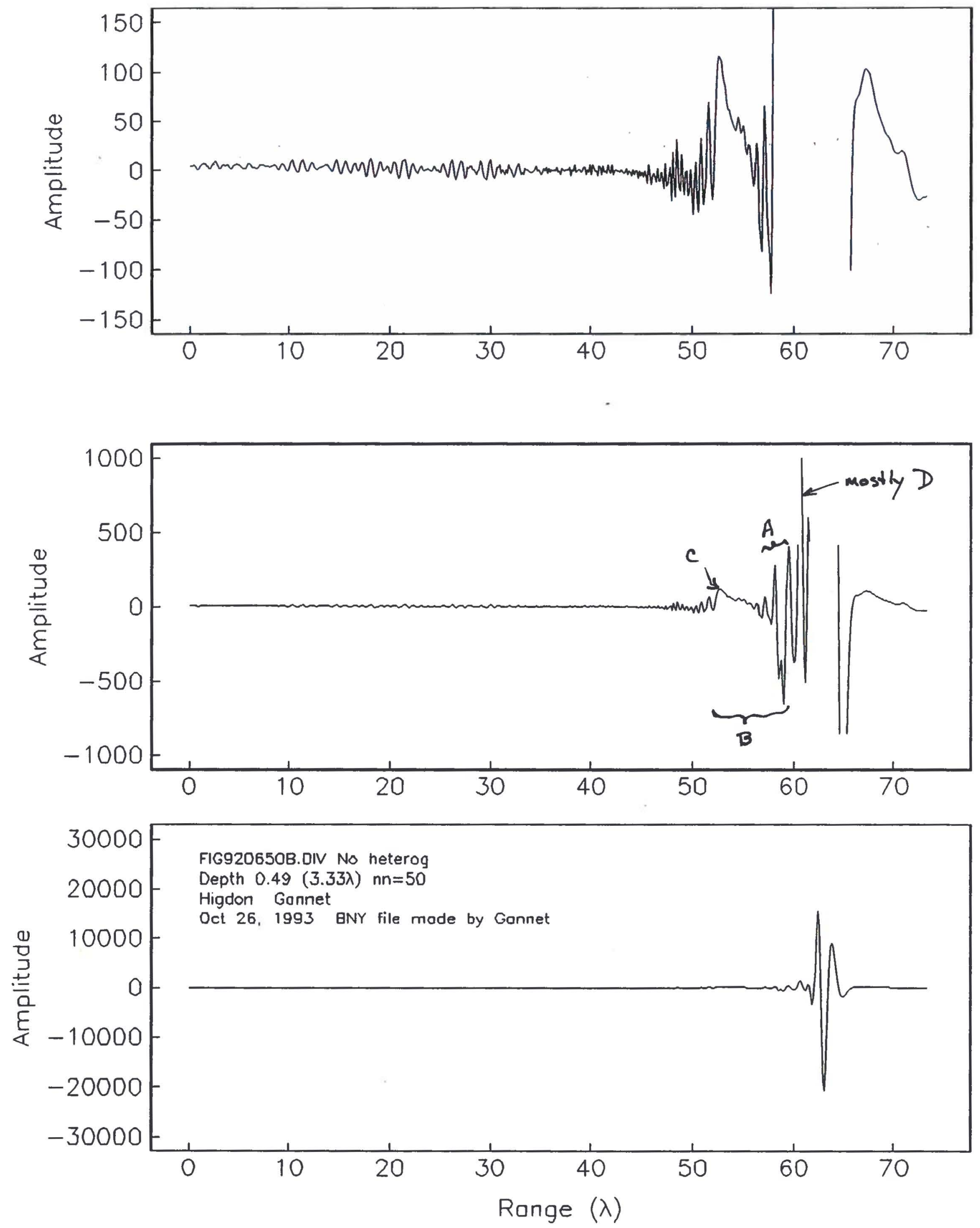
Figure 2c. Fif890500hgd. $k a=1$. Higdon boundaries.
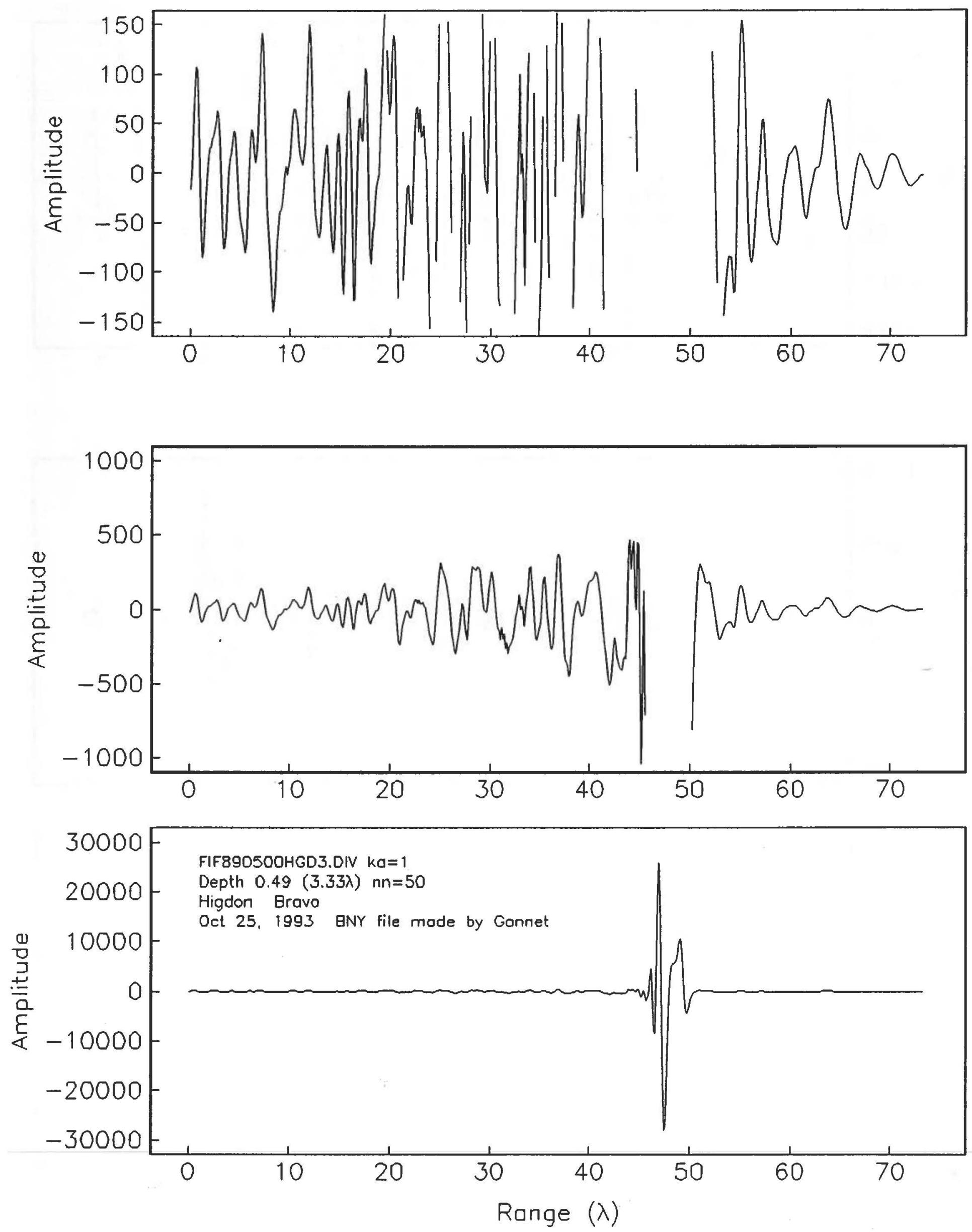
Figure 2d. Fif890650hgd. $k a=1$. Higdon boundaries.
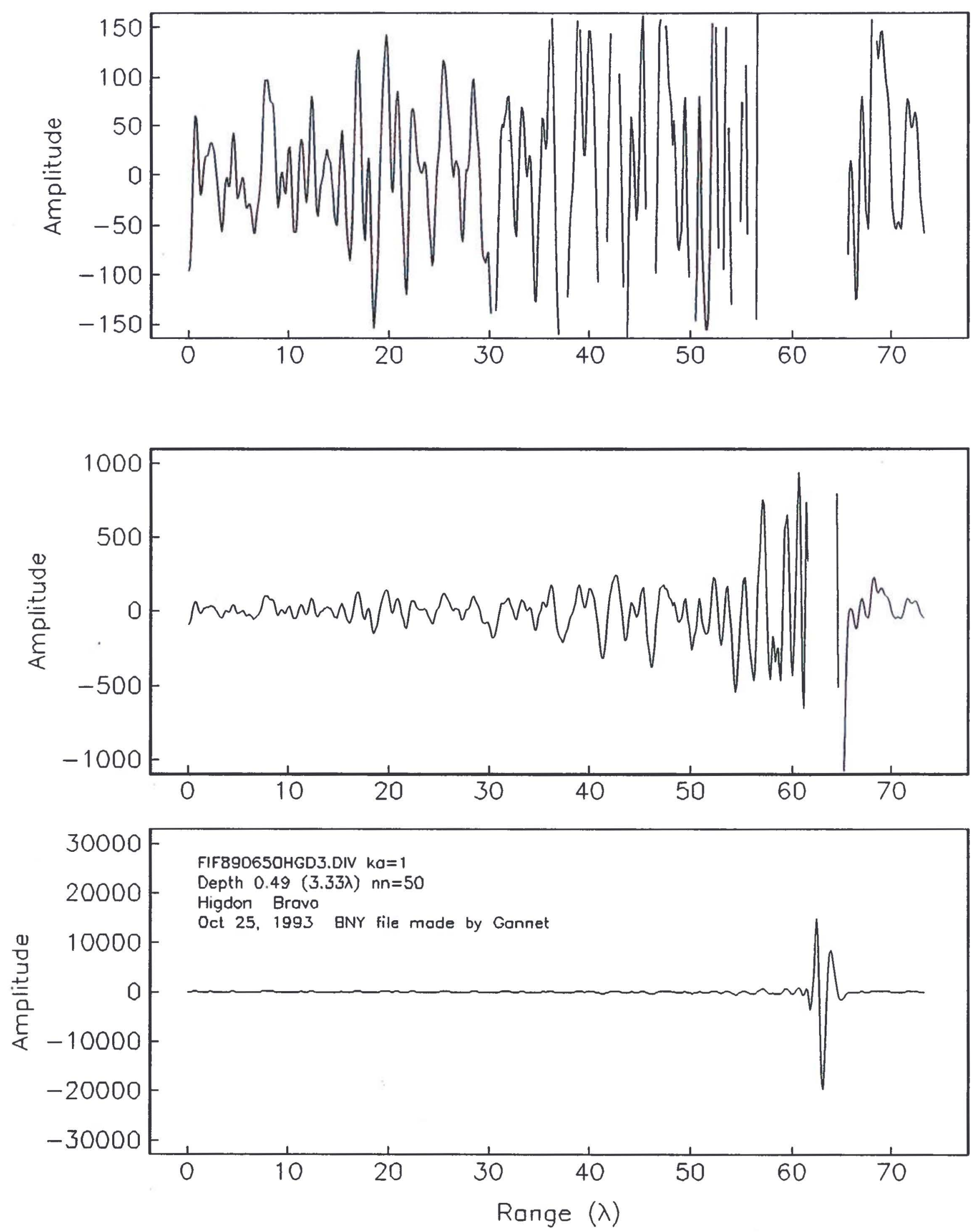
Figure 2e. Fifb60500. No heterogeneities. Telegraph Eqn boundaries. Convex.
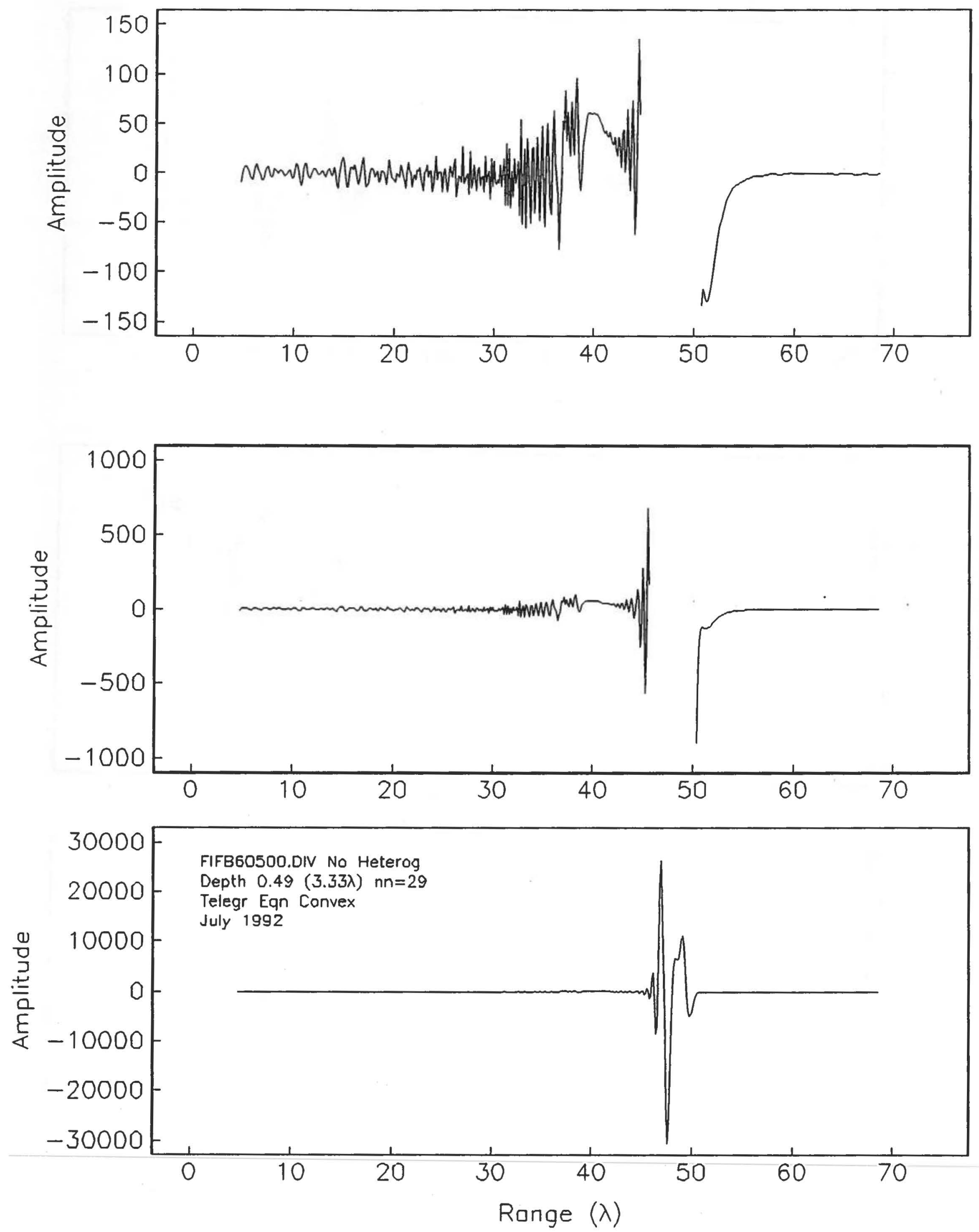
Figure 2f. Fifb60650. No heterogeneities. Telegraph Eqn boundaries. Convex.
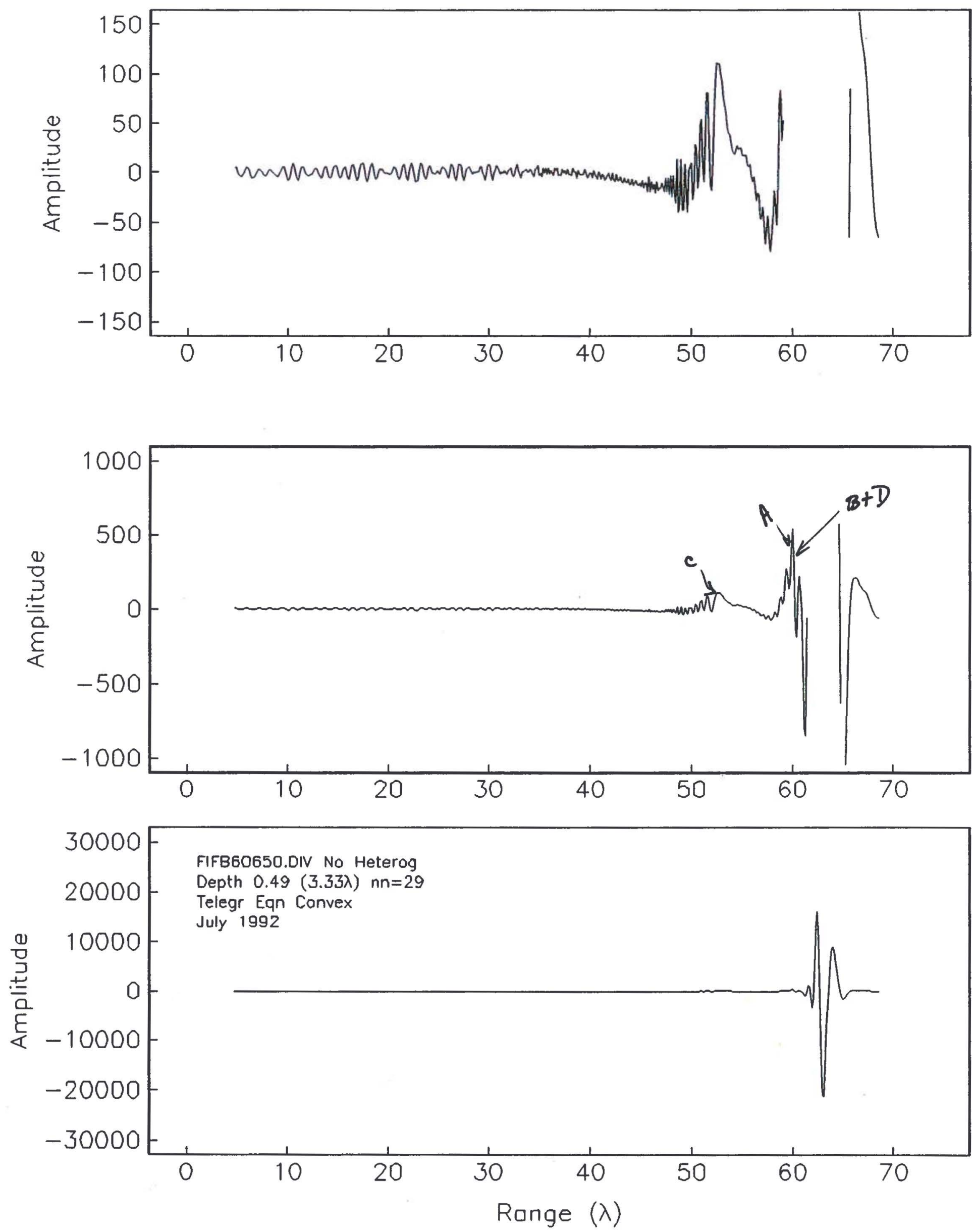
Figure 2h. Fig150650. No heterogeneities. Telegraph Eqn boundaries. Gannet
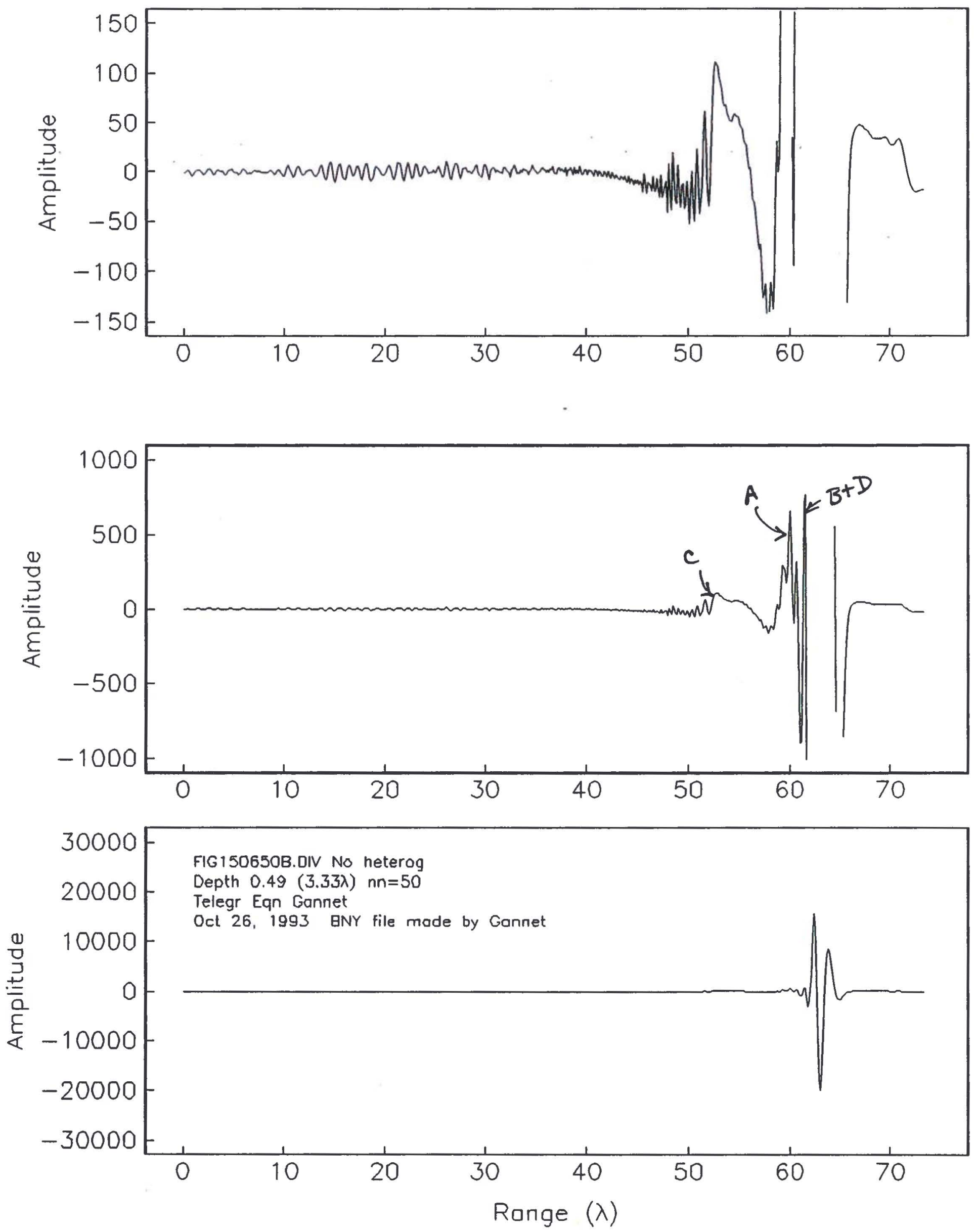
Figure 2i. Fif890500te. $k a=1$. Telegraph Eqn boundaries.
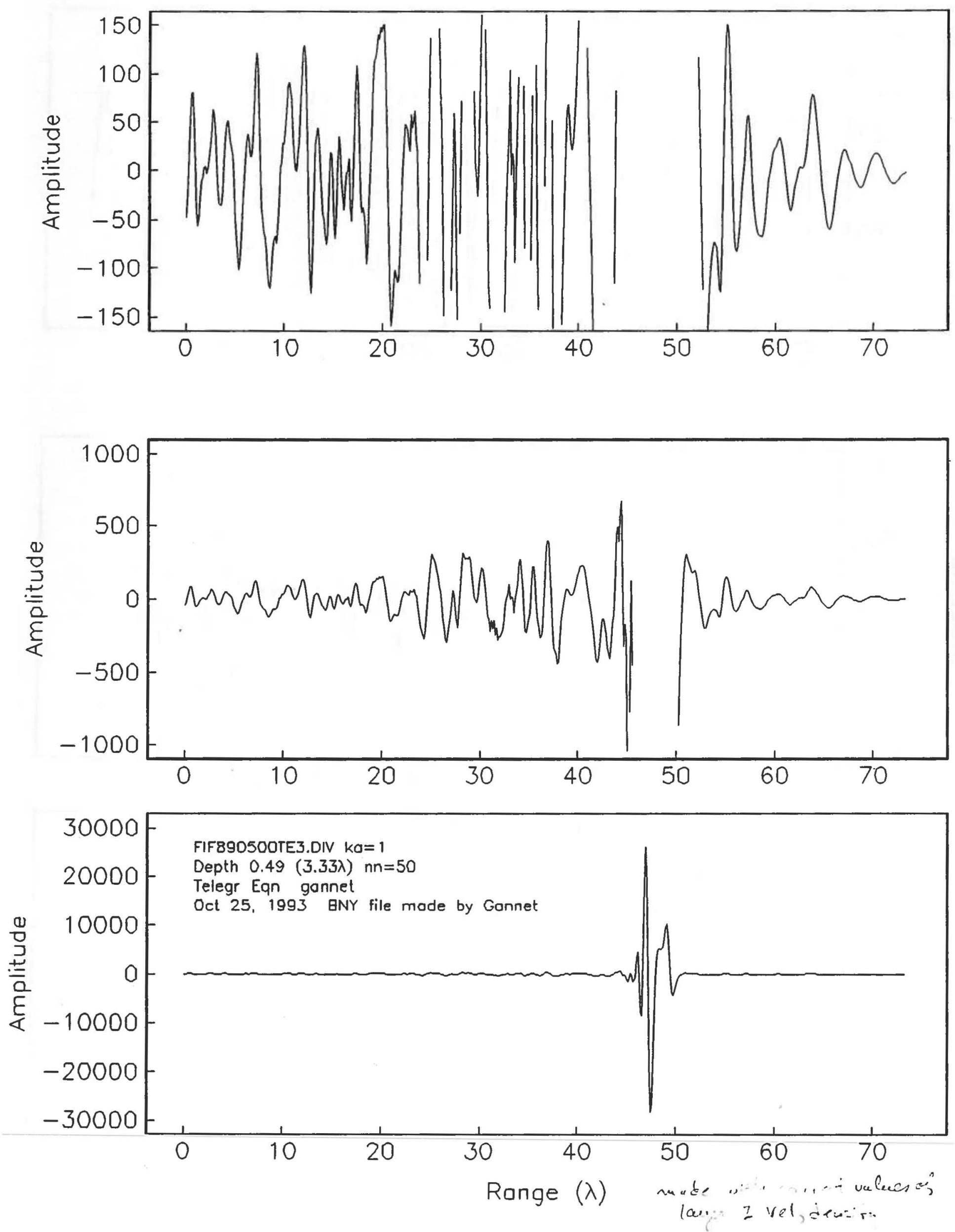
Figure 2j. Fif890650te. $k a=1$. Telegraph Eqn boundaries.
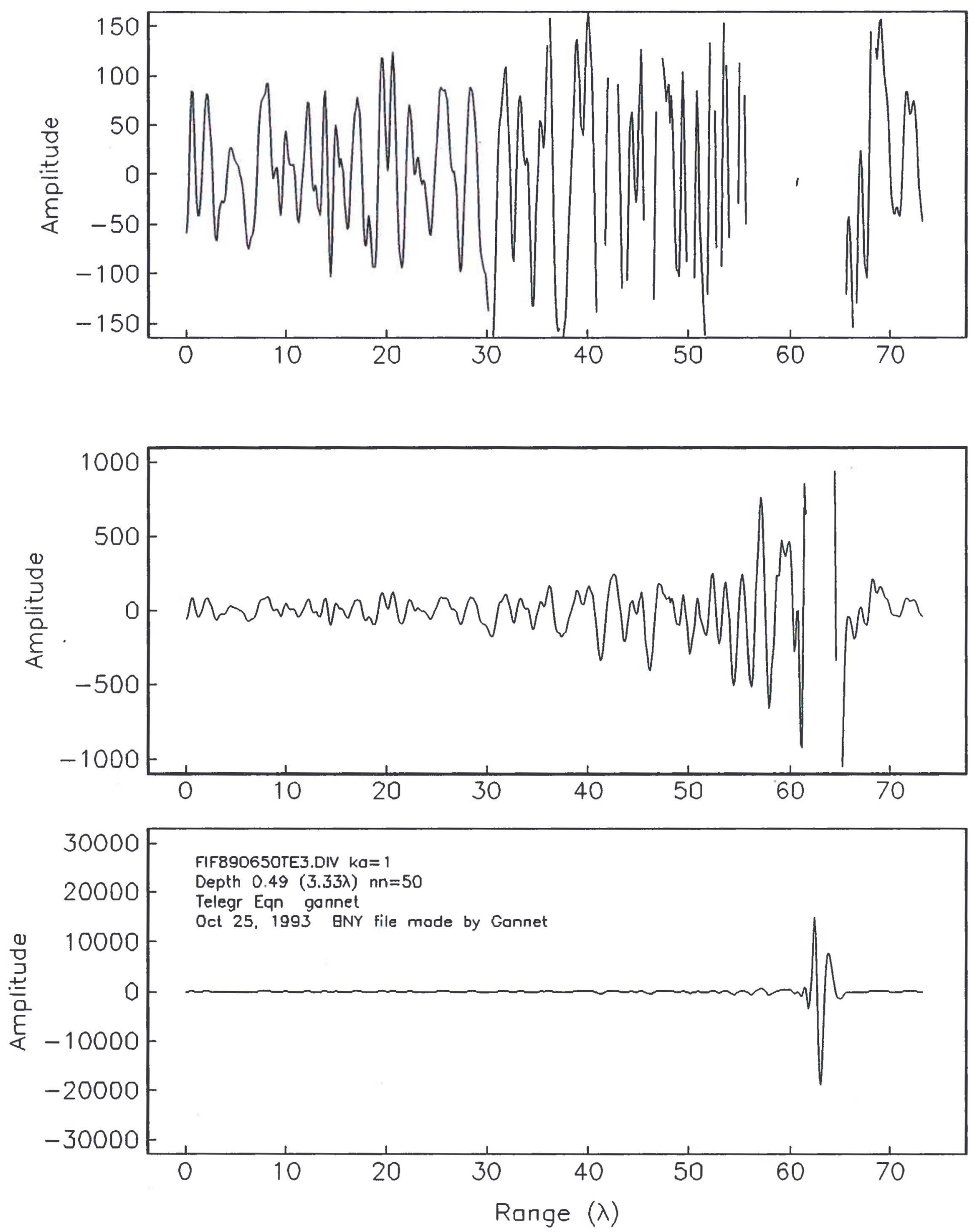


\section{Higdon Boundaries}

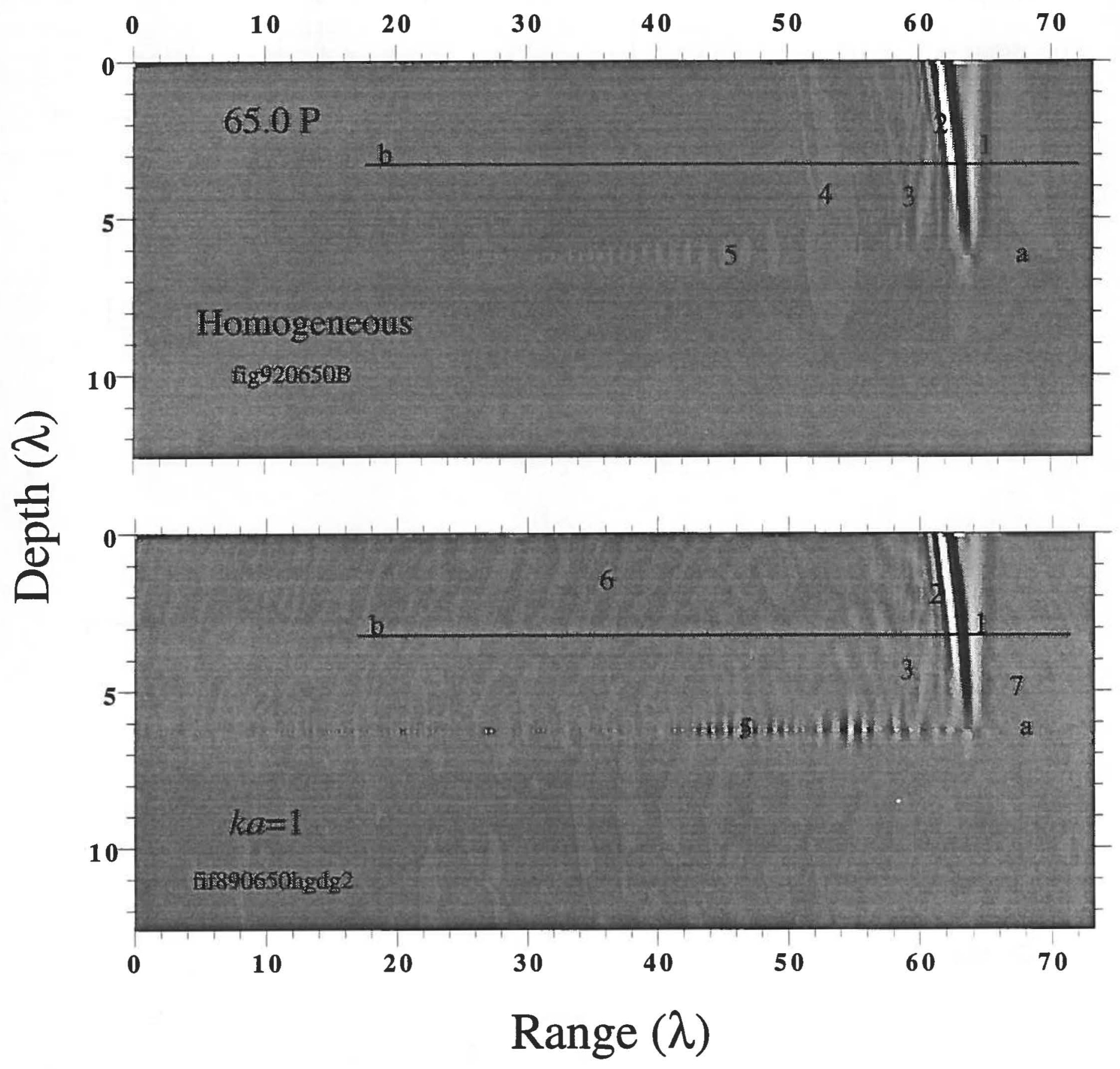

Figure 3: Representative snapshots from Figure 1 are shown with labels to indicate features that were examined quantitatively: 1 - direct wave; 2 - primary seafloor reflection; 3 - first abosrbing boundary multiple and second seafloor reflection; 4 - second absorbing boundary multiple and third seafloor reflection; 5 - interface waves; 6 - back scattered diffractions; 7 head waves. Also labeled are the seafloor (a) and the reference horizon in the water along which amplitude levels were measured (b). 
FIF890500HGDG2.HDF

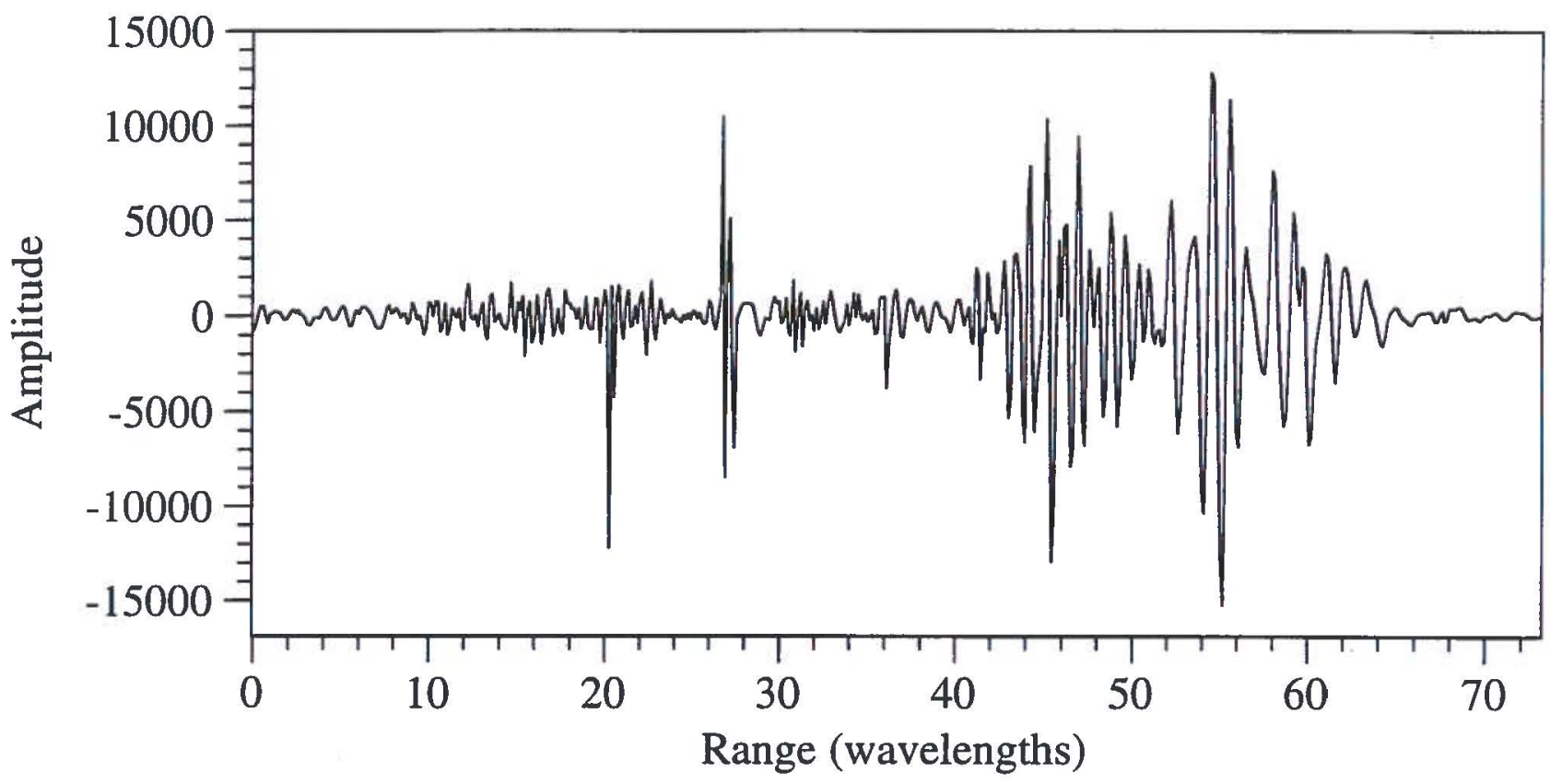

FIG920650B.HDF

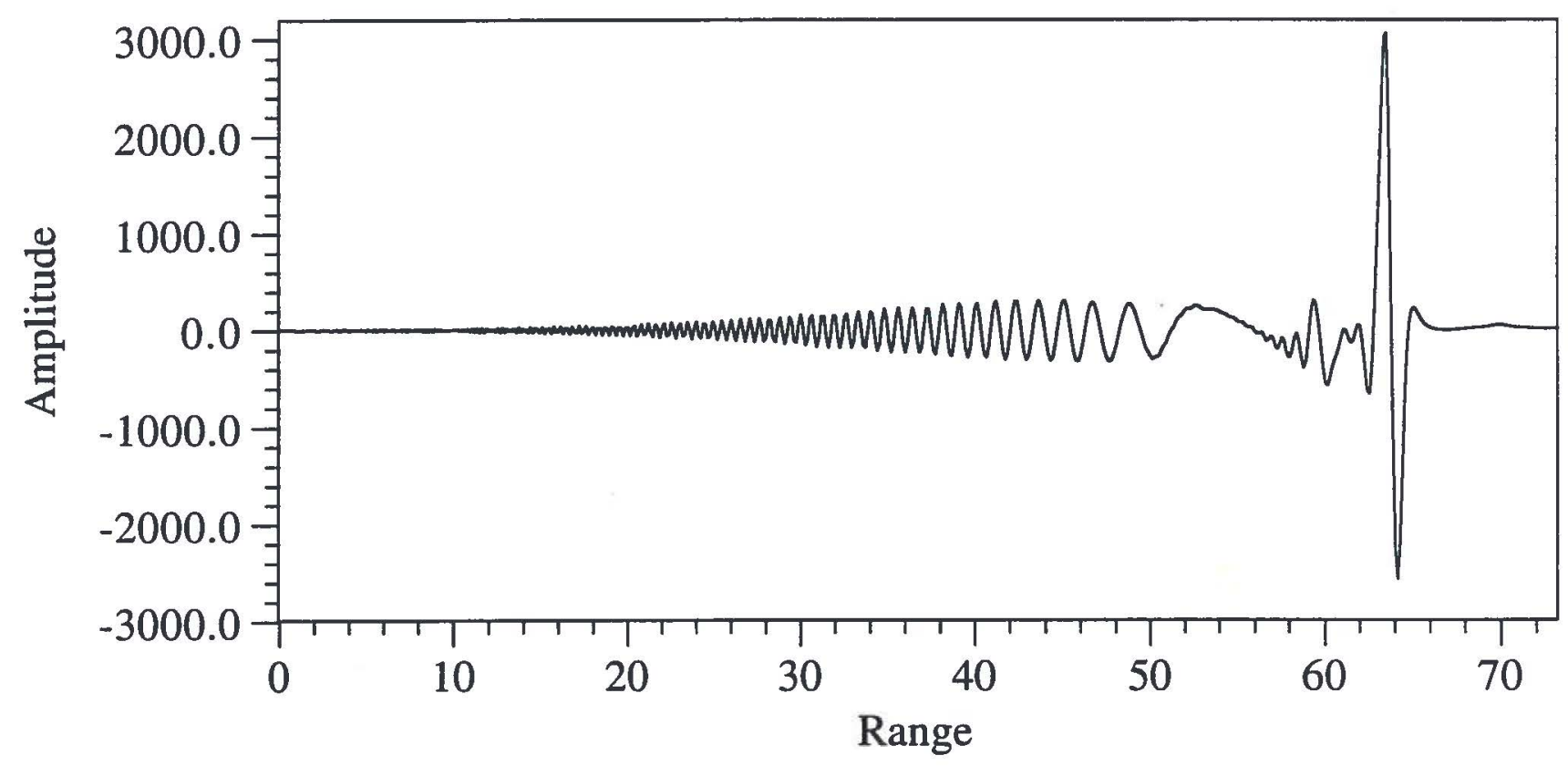

Figure 4. Data traces along the grid row at the top of basement. At this level interface waves reach their maximum amplitude. The top frame shows Stoneley waves in a model with lateral velocity heterogeneities in basement ( $\mathrm{ka}=1$, Fif890500hgd). The lower frame shows noise in a model with homogeneous basement (Fig920650). Note the difference in amplitude scales of the two frames. 
Table 1. Summary of models used in amplitude study.

\begin{tabular}{|c|c|c|c|}
\hline $\begin{array}{l}\text { Name } \\
\text { f Model }\end{array}$ & $\begin{array}{l}\text { Type of } \\
\text { Boundary }\end{array}$ & Computer & Date \\
\hline
\end{tabular}

FIFB6 Telegr Eq'n Convex July '92 -- $\quad$ Binary ?

- laterally homogeneous

$\begin{array}{llllll}\text { FIG15 Telegr Eq'n } & \text { Gannet } & \text { Oct. 26 '93 } & -- & \text { Ascii } & \text { bf9fif98 }\end{array}$

- laterally homogeneous

FIF 89/TE $\quad$ Telegr Eq'n $\quad$ Gannet $\quad$ Oct 25' $93 \quad 1 \quad$ Ascii $\quad$ bf9fif96

- heterogeneous

FIF89/HGD Higdon

Gannet Oct 25, '93 $1 \quad$ Ascii

bf9fif 96

- heterogeneous

FIG92 Higdon

Gannet Oct 26' $93 \quad$-- $\quad$ Ascii

bf9fif98

- laterally homogeneous 
Z

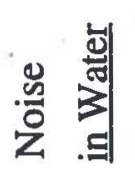

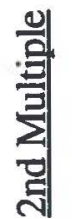

렬

을

离

융

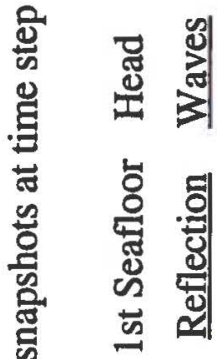

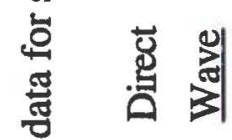

总

กี่

กับ
울

$n$
+1
0
0
0
+1

앙 우

$\sim$

- $\quad 8$

$\begin{array}{ll}8 & 8 \\ 8 & 8 \\ 8 & 1 \\ 0 & 1 \\ 0 & \\ 0 & \\ 01 & \end{array}$

- $\frac{\text { กิ }}{71}$

요

กิ

ஓ्र 8

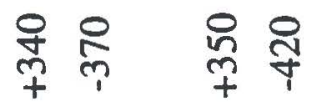

กิ

กิ

움

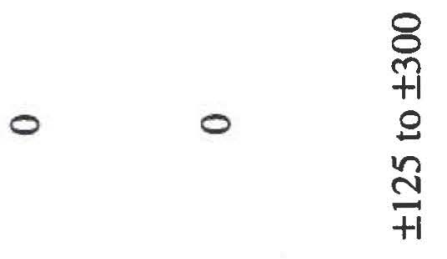

- $0 \quad \begin{aligned} & 0 \\ & 0 \\ & 0 \\ & 0 \\ & 0 \\ & 0 \\ & 01\end{aligned}$

ำ

000

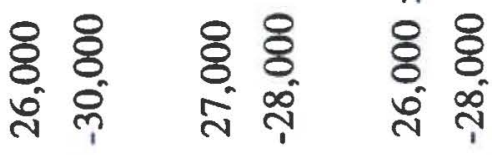

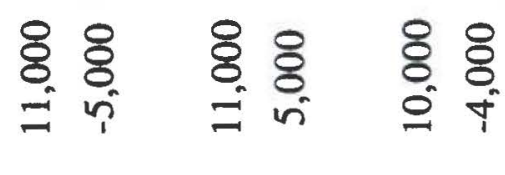

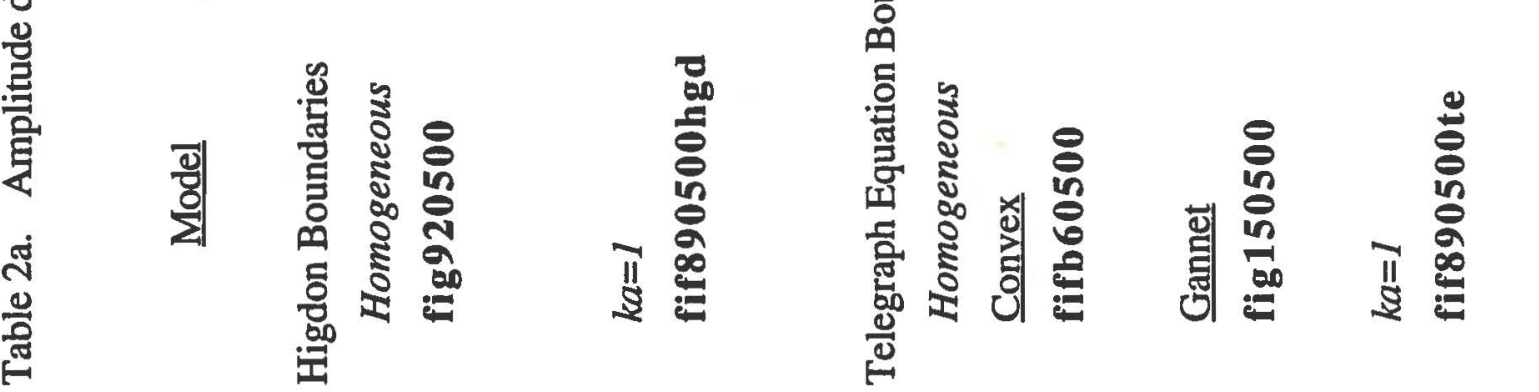


볼

各 윰

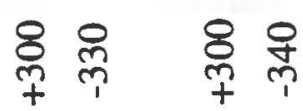

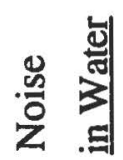

$\frac{0}{+1}$

$\circ$

$\stackrel{ }{+1}$

$\stackrel{ }{+1}$

薃

윰 움

윰 유 윰 무

言

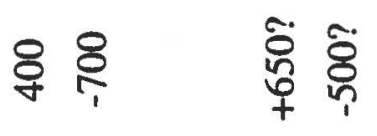

辤

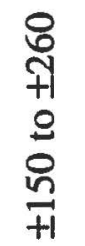

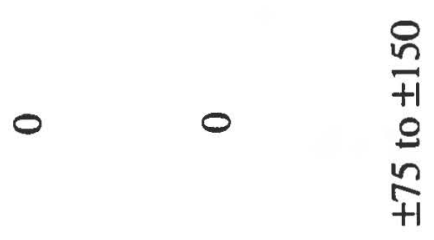

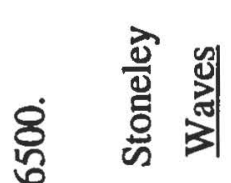

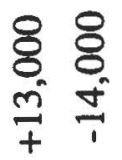

0
8
8
0
+1

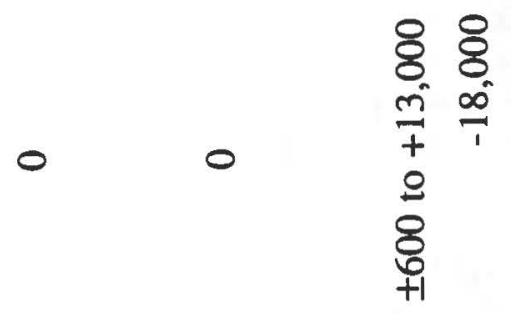

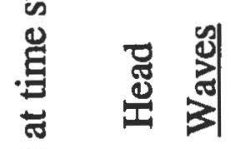

- $\quad \frac{0}{+1}$

- $0 \quad \frac{1}{4}$

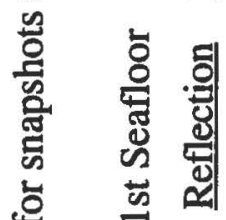

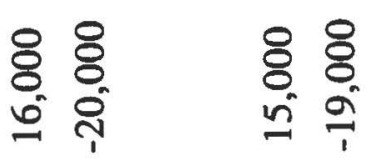

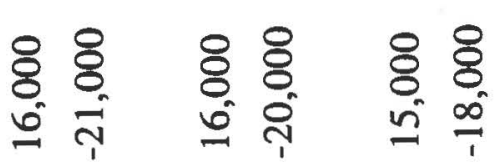

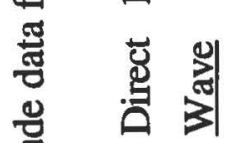

옹 8

\&:

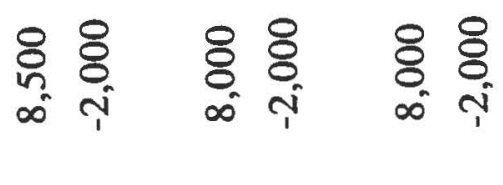

ลิ

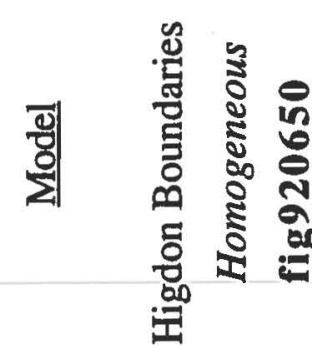

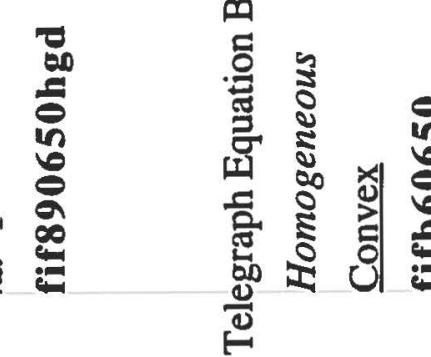

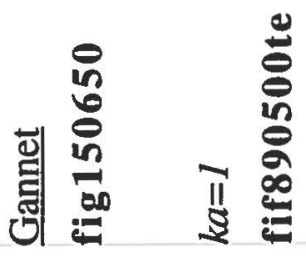


Appendix I. Parameter files and the LG1 log files for each model as available.

\title{
FIFB6.PAR
}

\author{
'FIFB6' \\ 1301, 401, 7501, 1 \\ $0.001,0.01,0.01$ \\ $1.5,0.0,1.0$ \\ $3.0,1.73,1.7$ \\ $0.0,0.0,0.0$ \\ $94,95,190,15 ., 3.91$ \\ $14,657 ., 0.0$ \\ $1,7501,4$ \\ $11,1091,30$ \\ $5,185,5$ \\ $0,5,500,500$ \\ $1,3,3$ \\ $0.00001,0.0125,180$ \\ $-1,-3,93$ \\ $20,20,0.0002,2.0$
}

\section{FIG15.PAR}

\section{'FIG15'}

$1301,401,6501,1$

$0.001,0.01,0.01$

$1.5,0.0,1.0$

$3.2,1.8475,1.4642$

$0.0,0.0,0.0$

$5,184,190,15 ., 3.91$

$14,657 ., 0.0$

$1,6501,4$

$11,1091,2$

$5,185,1$

$0,5,5000,500$

$1,1,3$

$0.00001,0.0125,180$

$-1,-3,93$

$20,20, .0002,2.0$ 


\section{FIG15.LG1}

PROGRAM FDPREP

VERSION OF 05-MAR-90

FILE ID IS FIG15

VALUES OF INPUT PARAMETERS:

$$
\begin{aligned}
& \text { ISORB }=1 \quad \text { IVERT }=1 \quad \text { ISNST }=3 \\
& \mathrm{MM}=1301 \quad \mathrm{NN}=401 \quad \mathrm{KK}=6501 \quad \mathrm{KSTRT}=1 \\
& \mathrm{NA}=5 \quad \mathrm{NB}=184 \quad \mathrm{MD}=1 \mathrm{ND}=1 \\
& \mathrm{DELT}=0.001000 \quad \mathrm{DELR}=0.0100 \mathrm{DELZ}=0.0100 \\
& \mathrm{ALP}=0.0000 \quad \text { ALPBOT }=0.0125 \mathrm{NALPWTH}=180 \\
& \mathrm{KLOOPS}=-1 \mathrm{KLOOPE}=-3 \mathrm{NDEPSORS}=93 \\
& \mathrm{QP}=20.0 \quad \mathrm{QS}=20.0 \\
& \text { TAU1 }=0.0002 \quad \text { TAU2 }=2.0000
\end{aligned}
$$

OUTPUT SPANS AND INCREMENTS:

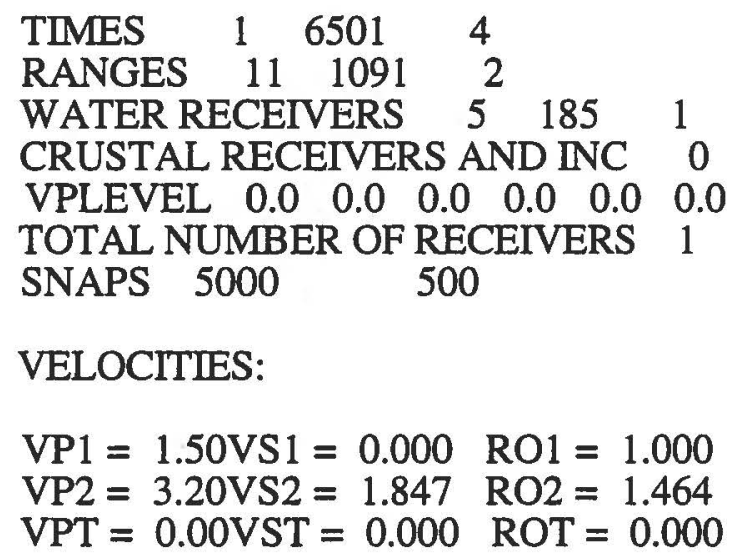

GRID WIDTH ABOVE SOURCE IS : 190

PROGRAM HAS CHANGED KSTRT $=1$ AND KKSORS $=5907$

KELLY SOURCE PARAMETERS:

NSORCE $=14$ PLSWID $=657.0 \mathrm{TSWAVE}=0.1460$

INCIDENT ANGLE $=15.000 \quad$ GAUSSIAN BEAM WIDTH $=3.910$

DIMENSION FOR ARRAYS

FOR A AND B: 13014012

FOR AR AND BR: $1301 \quad 190 \quad 2$

FOR A1DATA: $724 \quad 11627$

FOR A2DATA: 1111

FOR SORSA AND SORSB: 1301

FOR SORSAR AND SORSBR: 1301

FOR VP32 AND VS32: $1301 \quad 182$

FOR RO3: 1301182

FOR ZTP, ZTD, AND ZTXZ: 11

FOR ZTPRR, ZTDRR, AND ZTXZRR: 11

FOR IRECLOC: 5411 


\section{FIF89.PAR (TE)}

\section{'FIF89'}

$1301,401,6501,1$

$0.001,0.01,0.01$

$1.5,0.0,1.0$

$3.2,1.8475,1.4642$

$0.0,0.0,0.0$

$5,184,190,15 ., 3.91$

$14,657 ., 0.0$

$1,6501,4$

$11,1091,2$

$5,185,1$

$0,5,5000,500$

$1,1,3$

$0.00001,0.0125,180$

$-1,-3,93$

$20,20, .0002,2.0$ 
FIF89.LG1 (TE)

PROGRAM FDPREP

VERSION OF 05-MAR-90

FILE ID IS FIF89

VALUES OF INPUT PARAMETERS:

ISORB $=1 \quad$ IVERT $=1 \quad$ ISNST $=3$

$\mathrm{MM}=1301 \quad \mathrm{NN}=401 \quad \mathrm{KK}=6501 \quad \mathrm{KSTRT}=1$

$\mathrm{NA}=5 \quad \mathrm{NB}=184 \quad \mathrm{MD}=1 \mathrm{ND}=1$

DELT $=0.001000 \quad$ DELR $=0.0100$ DELZ $=0.0100$

$\mathrm{ALP}=0.0000 \quad$ ALPBOT $=0.0125 \mathrm{NALPWTH}=180$

$\mathrm{KLOOPS}=-1 \mathrm{KLOOPE}=-3 \mathrm{NDEPSORS}=93$

$\mathrm{QP}=20.0 \quad \mathrm{QS}=20.0$

TAU1 $=0.0002 \quad$ TAU2 $=2.0000$

OUTPUT SPANS AND INCREMENTS:

$\begin{array}{llll}\text { TIMES } & 1 & 6501 & 4 \\ \text { RANGES } & 11 & 1091 & 2\end{array}$

$\begin{array}{llll}\text { RANGES } & 11 & 1091 & 2\end{array}$

$\begin{array}{llll}\text { WATER RECEIVERS } & 5 & 185 & 1\end{array}$

CRUSTAL RECEIVERS AND INC $0 \quad 5$

$\begin{array}{lllllllllll}\text { VPLEVEL } & 0.0 & 0.0 & 0.0 & 0.0 & 0.0 & 0.0 & 0.0 & 0.0 & 0.0 & 0.0\end{array}$ TOTAL NUMBER OF RECEIVERS

SNAPS $5000 \quad 500$

VELOCITIES:

$\begin{array}{lll}\text { VP1 } & =1.50 \mathrm{VS} 1=0.000 & \text { RO } 1=1.000 \\ \text { VP2 }=3.20 \text { VS } 2=1.847 & \text { RO2 }=1.464 \\ \text { VPT }=0.00 V S T & =0.000 & \text { ROT }=0.000\end{array}$

GRID WIDTH ABOVE SOURCE IS : 190

PROGRAM HAS CHANGED KSTRT $=1$ AND KKSORS $=5907$

KELLY SOURCE PARAMETERS:

NSORCE $=14$ PLSWID $=657.0 \mathrm{TSWAVE}=0.1460$

INCIDENT ANGLE $=15.000 \quad$ GAUSSIAN BEAM WIDTH $=3.910$

DIMENSION FOR ARRAYS

FOR A AND B: 13014012

FOR AR AND BR: $1301 \quad 190 \quad 2$

FOR A1DATA: $724 \quad 1 \quad 1627$

FOR A2DATA: 111

FOR SORSA AND SORSB: 1301

FOR SORSAR AND SORSBR: 1301

FOR VP32 AND VS32: $1301 \quad 182$

FOR RO3: 1301182

FOR ZTP, ZTD, AND ZTXZ: 11

FOR ZTPRR, ZTDRR, AND ZTXZRR: 11

FOR IRECLOC: 5411 


\section{FIF89.PAR (HGD)}

\section{'FIF89'}

$1301,401,6501,1$

$0.001,0.01,0.01$

$1.5,0.0,1.0$

$3.2,1.8475,1.4642$

$0.0,0.0,0.0$

5, 184, 190, 15., 3.91

$14,657 ., 0.0$

$1,6501,4$

$11,1091,2$

$5,185,1$

$0,5,5000,500$

$1,1,3$

$0.00001,0.0125,180$

$-1,-3,93$

$20,20, .0002,2.0$ 


\section{FIF89.LG1 (HGD)}

PROGRAM FDPREP VERSION OF 05-MAR-90

FILE ID IS FIF89

VALUES OF INPUT PARAMETERS:

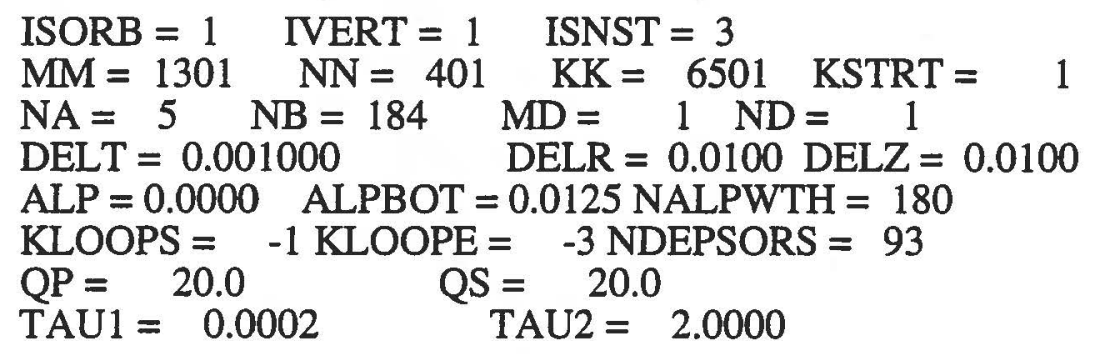

OUTPUT SPANS AND INCREMENTS:

$\begin{array}{llcc}\text { TIMES } & 1 & 6501 & 4 \\ \text { RANGES } & 11 & 1091 & 2\end{array}$

$\begin{array}{llll}\text { WATER RECEIVERS } & 5 & 185 & 1\end{array}$

CRUSTAL RECEIVERS AND INC $0 \quad 5$

$\begin{array}{lllllllllll}\text { VPLEVEL } & 0.0 & 0.0 & 0.0 & 0.0 & 0.0 & 0.0 & 0.0 & 0.0 & 0.0 & 0.0\end{array}$

TOTAL NUMBER OF RECEIVERS 1

SNAPS $5000 \quad 500$

VELOCITIES:

$\begin{array}{ll}\mathrm{VP} 1=1.50 \mathrm{VS} 1=0.000 & \mathrm{RO} 1=1.000 \\ \mathrm{VP} 2=3.20 \mathrm{VS} 2=1.847 & \mathrm{RO} 2=1.464 \\ \mathrm{VPT}=0.00 \mathrm{VST}=0.000 & \mathrm{ROT}=0.000\end{array}$

GRID WIDTH ABOVE SOURCE IS : 190

PROGRAM HAS CHANGED KSTRT $=1$ AND KKSORS $=5907$

KELLY SOURCE PARAMETERS:

NSORCE $=14$ PLSWID $=657.0 \mathrm{TSWAVE}=0.1460$

INCIDENT ANGLE $=15.000$ GAUSSIAN BEAM WIDTH $=3.910$

DIMENSION FOR ARRAYS

FOR A AND B: 13014012

FOR AR AND BR: $1301190 \quad 2$

FOR A1DATA: $724 \quad 11627$

FOR A2DATA: 1111

FOR SORSA AND SORSB: 1301

FOR SORSAR AND SORSBR: 1301

FOR VP32 AND VS32: 1301182

FOR RO3: 1301182

FOR ZTP, ZTD, AND ZTXZ: 11

FOR ZTPRR, ZTDRR, AND ZTXZRR: 11

FOR IRECLOC: 5411 


\title{
FIG92.PAR
}

\author{
'FIG92' \\ 2001, 251, 6501, 1 \\ $0.001,0.01,0.01$ \\ $1.5,0.0,1.0$ \\ $3.2,1.8475,1.4642$ \\ $0.0,0.0,0.0$ \\ $5,184,15,15 ., 3.91$ \\ $14,657 ., 0.0$ \\ $1,6501,4$ \\ $11,1091,2$ \\ $5,185,1$ \\ $0,5,5000,500$ \\ $1,1,3$ \\ $0.0001,0.0,5$ \\ $-1,-3,93$ \\ $20,20, .0002,2.0$
}




\section{FIG92.LG1}

PROGRAM FDPREP

VERSION OF 05-MAR-90

FILE ID IS FIG92

VALUES OF INPUT PARAMETERS:

$$
\begin{aligned}
& \text { ISORB }=1 \quad \text { IVERT }=1 \quad \text { ISNST }=3 \\
& \mathrm{MM}=2001 \mathrm{NN}=251 \quad \mathrm{KK}=6501 \quad \mathrm{KSTRT}=1 \\
& \begin{array}{lll}
\mathrm{NA}=5 \quad \mathrm{NB}=184 & \mathrm{MD}=1 \mathrm{ND}=1 \\
\mathrm{DELT}=0.001000 & \mathrm{DELR}=0.0100 \mathrm{DELZ}=0.0100
\end{array} \\
& \text { ALP }=0.0001 \text { ALPBOT }=0.0000 \text { NALPWTH }=5 \\
& \text { KLOOPS }=-1 \mathrm{KLOOPE}=-3 \mathrm{NDEPSORS}=93 \\
& \mathrm{QP}=20.0 \quad \mathrm{QS}=20.0 \\
& \text { TAU1 }=0.0002 \quad \text { TAU2 }=2.0000
\end{aligned}
$$

OUTPUT SPANS AND INCREMENTS:

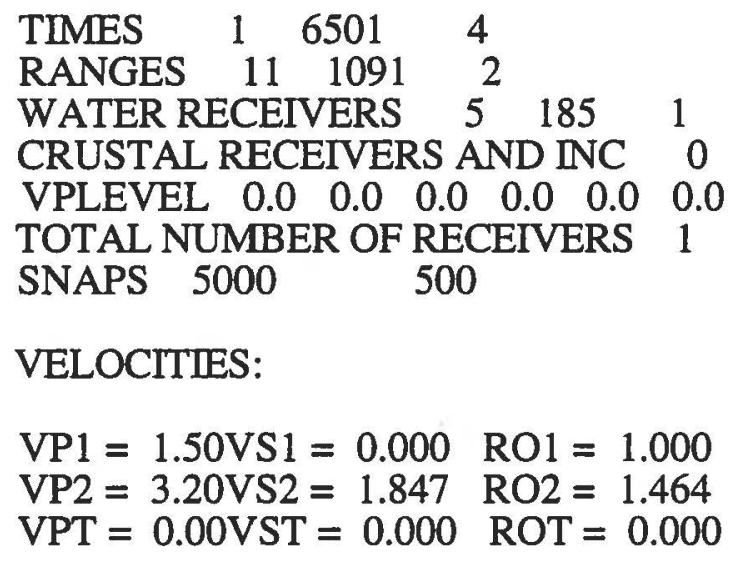

GRID WIDTH ABOVE SOURCE IS : 15

PROGRAM HAS CHANGED KSTRT $=1$ AND KKSORS $=5907$

KELLY SOURCE PARAMETERS:

NSORCE $=14$ PLSWID $=$ 657.0TSWAVE $=0.1460$

INCIDENT ANGLE $=15.000 \quad$ GAUSSIAN BEAM WIDTH $=3.910$

DIMENSION FOR ARRAYS

FOR A AND B: 20012512

FOR AR AND BR: $2001 \quad 15 \quad 2$

FOR A1DATA: $724 \quad 11627$

FOR A2DATA: 1111

FOR SORSA AND SORSB: 2001

FOR SORSAR AND SORSBR: 2001

FOR VP32 AND VS32: 2001182

FOR RO3: 2001182

FOR ZTP, ZTD, AND ZTXZ: 11

FOR ZTPRR, ZTDRR, AND ZTXZRR: 11

FOR IRECLOC: 5411 
